Gallón, N., Gómez, Y. y Rodríguez, M. (2020). Contabilidad popular. Una alternativa sociopráxica para resignificar las prácticas contables en las organizaciones de economía solidaria de Colombia. Contaduría Universidad de Antioquia, 77, 37-79.

Doi: https://doi.org/10.17533/udea.rc.n77a02

\title{
Contabilidad popular. Una alternativa socio-práxica para resignificar las prácticas contables en las organizaciones de economía solidaria de Colombia*
}

Natalia Gallón Vargas nataliagv6@gmail.com

Tecnológico de Antioquia orcid: 0000-0002-3298-3449

Yuliana Gómez Zapata

ygomezza@tdea.edu.co

Tecnológico de Antioquia orcid: 0000-0003-4134-4056

María Alejandra Rodríguez Triana maria.rtriana@gmail.com

Tecnológico de Antioquia orcid: 0000-0003-0003-537X

Artículo de investigación derivado del proyecto de investigación "Extensión solidaria. Prácticas contables para las organizaciones desde una propuesta de contabilidad popular". Financiado por el Tecnológico de Antioquia y adscrito a la Línea de Investigación en Contabilidad del Grupo de Investigación Observatorio Público. Agradecemos a Ecomún y a Santiago Ramírez por la confianza y por permitirnos acceder a la información para el desarrollo de esta investigación. 
Contabilidad popular. Una alternativa socio-práxica para resignificar las prácticas contables en las organizaciones de economía solidaria de Colombia

Resumen: El objetivo de este artículo es proponer la contabilidad popular como una alternativa socio-práxica para resignificar las prácticas contables en las organizaciones de economía solidaria de Colombia. Para su desarrollo se caracterizaron los enfoques y sentidos de la economía solidaria y sus expresiones organizacionales asociativas y se analizaron las dificultades y necesidades contables a partir del reconocimiento contextual y territorial de 12 organizaciones de economia solidaria de los excombatientes de las FARC-EP, que hacen parte del proceso de reincorporación económica colectiva promovido por Economías Sociales del Común (Ecomún). Es una investigación cualitativa, que se propone desde el paradigma socio-crítico y utiliza el método dialógico-conversacional y marcos sociales de interacción. Desde la aproximación teórico-conceptual que aquí se logró construir, la contabilidad popular es una práctica pedagógico-política y social que busca reafirmar y resignificar los conocimientos y prácticas contables que las organizaciones desarrollan para responder a sus necesidades y generar las condiciones para la emergencia de otras prácticas contables situadas con las organizaciones de economía solidaria, desde la educación popular como acción pedagógica, ético-política y como praxis de transformación.

Palabras clave: Contabilidad popular, organizaciones de economía solidaria, FARC-EP, educación popular, praxis.

Popular accounting. A socio-praxical alternative to resignify accounting practices in solidarity economy organizations in Colombia

Abstract: This paper aims at proposing popular accounting as a socio-praxis alternative to resignify accounting practices in solidarity economy organization in Colombia. To develop this study, the approaches and meaning of solidarity economy and its associative organizational expressions were characterized and the accounting difficulties and needs were analyzed from the contextual and territorial recognition of 12 solidarity economy organizations of FARC-EP ex combatants, who are part of the collective economic reintegration process promoted by Social Economies of the Commons (Ecomún). This is a qualitative research work, proposed from the socio-critical paradigm, and it uses the dialogic-conversational method and social frames of interaction. From the theoretical-conceptual approach built here, popular accounting is a pedagogical-political and social practice seeking to reaffirm and resignify the accounting knowledge and practices organizations develop to respond to their needs and generate the conditions for the emergence of other accounting practices situated within the solidarity economy organizations, from popular education as pedagogical, ethical-political action and as transformation praxis.

Keywords: Popular accounting, solidarity economy organization, FARC-EP, popular education; praxis.

Contabilidade popular. Uma alternativa socio-práxica para resignificar as práticas contábeis nas organizações de economia solidária da Colômbia

Resumo: $O$ objetivo deste artigo é propor a contabilidade popular como uma alternativa socio-práxica para resignificar as práticas contábeis nas organizações de economia solidária da Colômbia. Para o seu desenvolvimento foram caracterizados os enfoques e sentidos da economia solidária e as suas expressões organizacionais associativas $e$ analisaram-se as dificuldades e necessidade contábil a partir do reconhecimento contextual e territorial de 12 organizações da economia solidária dos ex-combatentes das FARC-EP, que fazem parte do processo de reincorporação económica coletiva promovido por Economias Sociais do Comum (ECOMUN). É uma pesquisa qualitativa, que se propõe desde o paradigma socio-crítico e utiliza o método dialógico-conversacional e marcos sociais de interação. Desde a aproximação teórico-conceitual que foi possível construir aqui, a contabilidade popular é uma prática pedagógico-política e social que procura reafirmar e resignificar os conhecimentos e práticas contábeis que as organizações desenvolvem para responder às suas necessidades e gerar as condições para a emergência de outras práticas contábiles situadas com as organizações de economia solidária, desde a educação popular como ação pedagógica, ético-política e como práxis de transformação.

Palavras-chave: Contabilidade popular, organizações de economia solidária, FARC-EP, educação popular, práxis.

Comptabilité populaire. Une alternative socio-pratique pour resignifier les pratiques comptables dans les organisations d'économie solidaire en Colombie

Résumé : cet article a pour but de proposer la comptabilité populaire en tant qu'alternative socio-pratique afin de resignifier les pratiques comptables dans les organisations d'économie solidaire en Colombie. Pour ce faire, les approches et sens de l'économie solidaire ont été caracterisés, ainsi que ses expressions organisationnelles associatives. Les difficultés et besoins comptables ont aussi été analysés à partir de la reconnaissance du contexte et du territoire de douze organisations d'économie solidaire des anciens combattants des FARCE-EP, qui font parti du processus de réinsertion économique collective promu par les Économies Sociales du Commun (Ecomún). Celle-ci est une recherche qualitative proposée à partir du paradigme socio-critique, et qui fait appel au modèle dialogique-conversationnelle ainsi que les cadres sociaux d'intéraction. Selon l'approche théorique-conceptuelle construite ici, la comptabilité populaire est une pratique pédagogique-politique et sociale cherchant à renforcer et à resignifier les savoir et les pratiques comptables que les organisations développent pour répondre aux besoins et générer des conditions pour le surgissement d'autres pratiques comptables situées avec les organisations d'économie solidaire, basée sur l'éducation populaire en tant qu'action pédagogique, éthico-politique et praxis de transformation.

Mots clés : Comptabilité populaire, organisations d'économie solidaire, FARC-EP, éducation populaire, praxis. 


\title{
Contabilidad popular. Una alternativa socio-práxica para resignificar las prácticas contables en las organizaciones de economía solidaria de Colombia
}

\author{
Natalia Gallón Vargas, Yuliana Gómez Zapata y María Alejandra Rodríguez Triana \\ https://doi.org/10.17533/udea.rc.n77a02
}

Primera versión recibida en marzo de 2020 - Versión aceptada en junio de 2020

\section{Introducción}

a categoría contabilidad popular emerge de la experiencia de trabajo Linvestigativo con la metodología de Círculos Solidarios, programa liderado por la Corporación Fomentamos de Medellín - Antioquia (Restrepo, Insuasty y Palacios, 2015; Gómez, Palacios y Restrepo, 2015). Los Círculos Solidarios son:

...grupos informales de personas de comunidades marginadas, autogestionarios, formados por los más pobres, especialmente mujeres, que se reúnen con el fin de acceder a crédito, ahorrar y generar espacios para la reflexión de la vida diaria. Sus integrantes son microemprendedores, con negocios de subsistencia. Es más que un crédito, es una oportunidad para hacer amigos. Es un grupo donde se comparten necesidades y aspiraciones. (Fomentamos, 2019)

Esta metodología se plantea desde la economía solidaria y toma como referentes la propuesta de microcréditos desarrollada en Bangladesh por el Nobel de Paz Muhammad Yunus, y la banca comunitaria del economista estadounidense John Hatch. Desde la experiencia investigativa se evidenció que la contabilidad popular es una denominación de las prácticas contables que han desarrollado los Círculos Solidarios ${ }^{1}$ y que surgen de las necesidades de supervivencia de los sujetos y actores que allí participan, con el propósito de apropiarse, a partir de sus prácticas cotidianas, sociales y experienciales, de las dinámicas contables de su actividad productiva o comercial.

1 La contabilidad popular también puede ser una denominación de las prácticas contables nombrada por otras organizaciones, pero desde la experiencia investigativa solo la conocemos en los Círculos Solidarios. 
Gallón, N., Gómez, Y. y Rodríguez, M. Contabilidad popular. Una alternativa socio-práxica...

El sentido de las prácticas contables no se comprende desde la dimensión financiera, sino que parte de las necesidades contextuales y se extiende hacia un campo de posibilidades como emergencias de realidades que no pasan por la matriz ontológica y epistemológica de ocultamiento (Santos, 2009; Escobar, 2013; Gil, 2018). Esta experiencia dejó ver las potencialidades de la contabilidad en organizaciones de economía solidaria y popular como un campo que se construye, resignifica y responde a los contextos y a la agencia de los sujetos, así como al poder de la contabilidad para incidir en estos. De igual manera, planteó la necesidad de reflexionar, crear y proponer metodologías y prácticas contables a partir del diálogo entre la práctica social como conocimiento y la práctica académica e investigativa.

A partir de lo anterior, desde hace cinco años hemos venido desarrollando una línea de investigación sobre la fundamentación teórica, metodológica y práctica de la categoría contabilidad popular. A partir de la extensión solidaria, hemos planteado un proyecto que busca proponer la categoría de contabilidad popular para resignificar las prácticas contables en las organizaciones de economía solidaria de Colombia. Particularmente, hemos trabajado con organizaciones del proceso de reincorporación de las Fuerzas Armadas Revolucionarias de Colombia (FARC-EP) y otras organizaciones sin ánimo de lucro. El proyecto se ha desarrollado en dos fases.

En la primera, realizamos una aproximación a la categoría indagando por el papel de la contabilidad en las organizaciones de economía solidaria, principalmente, describiendo la experiencia y metodología de Círculos Solidarios y la emergencia de la contabilidad popular. Caracterizamos las prácticas y herramientas contables que han construido los miembros de los Círculos Solidarios como parte del proceso de formación en contabilidad y economía solidaria para la gestión de sus unidades productivas (Rodríguez, Gallón y Gómez, 2016). La segunda fase está en curso; no obstante, como resultados parciales, señalamos un eje sobre el cual pensar la contabilidad popular y es la práctica pedagógica como un vértice para la reflexión y transformación de la práctica contable en las organizaciones de economía solidaria. Lo popular adquiere una connotación más amplia y no se limita a las condiciones de pobreza o marginalidad de un grupo social, sino que toma asidero en la pedagogía popular (Freire, 2005, 2011) como fuerza liberadora y práctica política, que sitúa a los sujetos en sus circunstancias históricas para ser agentes de cambio social (Rodríguez, Gallón y Gómez, 2018).

En este contexto, y como parte del proyecto que venimos desarrollando, hemos planteado la pregunta: ¿cuáles son las posibilidades de la contabilidad popular como alternativa socio-práxica para resignificar las prácticas contables en las organizaciones de economía solidaria de Colombia? Al indagar por las posibilidades de la contabilidad popular se hace referencia a los horizontes y 
caminos no lineales, sino sinuosos, que reafirman realidades y prácticas sociales y contables alternativas ya existentes, pero en los que también emergen posibilidades de otras realidades, otras formas de interexistencia (Escobar, 2013) y alternativas contables construidas en la esfera de la economía solidaria. Parafraseando a Santos $(2003 ; 2009 ; 2010)$ es la contabilidad de las ausencias y las emergencias.

Gran parte de la tradición en contabilidad ha sido entendida y desarrollada desde la dimensión financiera (Gómez y Ospina, 2009; Gómez, 2019). La contabilidad financiera, en mayor medida, hace parte de una arquitectura epistemológica, ontológica y cognitiva de ocultamiento e inexistencia (Gil, 2018). Soportada en la racionalidad cartesiana, el pensamiento único y el crecimiento ilimitado, la contabilidad reduce la realidad a lo que existe.

Como un conocimiento y un conjunto de estándares, herramientas y procedimientos homogéneos y neutrales, aplicables a cualquier tipo de organización, sin diferenciar el contexto y enfoque, y con la finalidad de ajustar las organizaciones a las prácticas y dinámicas contables de la empresa que se instaura bajo las leyes, principios y valores del capitalismo, la contabilidad valida los criterios de medición y representación de la realidad de la empresa de capital privado, pero que no responden a las necesidades contextuales, económicas y sociales de las organizaciones de economía solidaria, en el sentido de que no hay un reconocimiento de las realidades y prácticas propias de los sujetos que habitan las organizaciones de economía solidaria como espacios, no solo económicos, sino también epistémicos y políticos.

El objetivo de este artículo es proponer la contabilidad popular como una alternativa socio-práxica para resignificar las prácticas contables en las organizaciones de economía solidaria de Colombia. Para su desarrollo se caracterizan los enfoques y sentidos de la economía solidaria y sus expresiones organizacionales asociativas. De igual manera, se analizan las dificultades y necesidades contables a partir del reconocimiento contextual y territorial de 12 organizaciones de economía solidaria de los excombatientes de las FARC-EP, que hacen parte del proceso de reincorporación económica colectiva promovido por Economías Sociales del Común (Ecomún). Dentro de las organizaciones se encuentran cooperativas, corporaciones y asociaciones, ubicadas en los Espacios Territoriales de Capacitación y Reincorporación (ETCR) y Nuevos Puntos de Reagrupamiento (NPR), ${ }^{2}$ de los departamentos de Chocó, La Guajira, Cesar, Cauca y Bolívar. Finalmente, se presentan las características teórico-conceptuales de la contabilidad popular como alternativa socio-práxica.

El acercamiento y trabajo con las organizaciones de economía solidaria de los reincorporados de las FARC-EP se ha dado por medio de Ecomún y su

2 Hace referencia a los nuevos espacios colectivos conformados por exintegrantes de las FARC-EP que decidieron salir de los ETCR, pero que siguen en el proceso de reincorporación económica y social. 
Gallón, N., Gómez, Y. y Rodríguez, M. Contabilidad popular. Una alternativa socio-práxica...

necesidad de impulsar una estrategia de apoyo en la comprensión, construcción y aplicación de prácticas contables con las unidades productivas. El encuentro se ha dado a partir de la afinidad con el proyecto y la confianza, pues desde la extensión solidaria se ha buscado un acercamiento con las organizaciones de economía solidaria para comprender sus prácticas y responder a sus necesidades contables desde la horizontalidad y la participación de los actores de las organizaciones.

Las organizaciones de economía solidaria son la estrategia de reincorporación económica colectiva de las FARC-EP; es su apuesta por la construcción de paz desde la economía solidaria como alternativa al modelo de desarrollo capitalista. Es la voluntad de paz de los excombatientes y de cumplir lo negociado en el Acuerdo Final. ${ }^{3}$ De nuestra parte, creemos en el proceso de reincorporación económica, social y política de las FARC-EP como salida al conflicto armado y como expresión de construcción de paz en los territorios y con las comunidades para la reconstrucción del tejido social, la reconciliación y el ejercicio de lo político desde el poder de las ideas. En este sentido, es una declaración de intenciones políticas y una responsabilidad como contadores y contadoras públicas de contribuir, apoyar y construir, a partir de la contabilidad popular y la investigación crítica y participativa, estrategias, metodologías, prácticas y herramientas que permitan desarrollar y potenciar lo contable con las organizaciones de economía solidaria de los excombatientes de las FARC-EP.

La importancia y pertinencia de la propuesta de la contabilidad popular responde a las posibilidades de: ser un campo construido a partir de las prácticas cotidianas y experiencias vivas como saberes y conocimientos situados de los sujetos organizados bajo formas alternativas de economía; reivindicar los contextos y el enfoque territorial de las organizaciones de economía solidaria para la emergencia de prácticas contables de acuerdo con las necesidades particulares y las condiciones que inciden en las organizaciones; responder a la praxis y agencia de los sujetos, lo cual supone su protagonismo en el proceso de pensar, reflexionar de manera crítica y recrear las prácticas contables. La contabilidad popular tiene sentido y se constituye en la educación popular como postura epistémico política y acción pedagógica, que posibilita procesos de formación a partir de la experiencia, la concienciación y la voluntad de los sujetos; proceso que también incide en la subjetivación al propiciar las condiciones para ampliar las capacidades y potencialidades de los sujetos en la autogestión de las organizaciones de economía solidaria.

La contabilidad popular se presenta en términos de posibilidades, pero también es acción y reflexión; es praxis que se transforma en la interacción e interrelación de los sujetos y sus saberes en la esfera de las organizaciones de

3 Acuerdo final para la terminación del conflicto y la construcción de una paz estable y duradera, firmado entre el Gobierno Nacional y las FARC-EP en 2016. 
economía solidaria. En este sentido, representa un reto en la manera de hacer investigación y en el vínculo entre la academia contable y las organizaciones, pues exige repensar y recrear nuevas posturas epistemológicas y diseños metodológicos, incluso los que hacen parte de la tradición crítica en ciencias sociales y, de manera particular, del campo de la contabilidad.

El artículo se compone de un diseño y justificación de la estrategia metodológica, seguido del desarrollo de cada uno de los objetivos que corresponden a tres capítulos. El primer capítulo caracteriza la economía solidaria y sus figuras asociativas. Seguido de la contabilidad en las organizaciones de economía solidaria desde una mirada contextual, en el que se presentan y analizan las dificultades y necesidades contables de las organizaciones de economía solidaria de los excombatientes de las FARCEP e indaga por el sentido de la contabilidad financiera en este tipo de organizaciones. El último capítulo desarrolla las aproximaciones teóricoconceptuales de la contabilidad popular. El texto finaliza con las conclusiones.

\section{La estrategia metodológica de investigación}

\section{II.I. La justificación del tipo y método}

Investigar interpela por el sentido de la realidad y los lugares desde donde los sujetos piensan y comprenden esa realidad; es decir, exige un posicionamiento epistemológico. También está relacionado con la pertinencia histórica del conocimiento que se construye, en consecuencia, la capacidad y potencialidad para responder a las condiciones contextuales y relaciones espacio-temporales en términos de comprensión y transformación de las realidades (Zemelman, 2005).

En esta investigación de tipo cualitativo, la postura epistemológica se inscribe en el paradigma socio-crítico, el cual lleva a definir unos sentidos y relaciones con la realidad y el conocimiento de manera particular. En primer lugar, las realidades no existen per se, "nada existe por sí solo, todo interexiste" (Escobar, 2013, p. 20). Es justamente la comprensión de las realidades como una interrelación en un todo complejo, definido por condiciones del espacio-tiempo y en las que los sujetos participan como productores de sentidos, lo que lleva a afirmar que "las ontologías no preceden ni existen independientemente de nuestras prácticas cotidianas" (Escobar, 2013, p.26).

En segundo lugar, contrario a la tradición racionalista, cartesiana y reduccionista del conocimiento y la realidad, en la que se ocultan otras formas de ser y conocimientos para convertirlas en alternativas no creíbles a lo existente o que por su arquitectura epistémica no las ven (Escobar, 2013; Santos 2009), se hace necesario reivindicar formas de conocer emergentes, de borde o frontera (Torres, 2008; 2009), en las que el rescate de los sujetos, las 
Gallón, N., Gómez, Y. y Rodríguez, M. Contabilidad popular. Una alternativa socio-práxica...

subjetividades sociales y la práctica social como conocimiento configuran una episteme ética y política, dirigida a la apertura de nuevas realidades y prácticas emancipadoras. Por último, indagar por el sentido de la investigación parte de cuestionar el para qué y el para quién, de ahí que se busque la pertinencia en términos de generar cambios o transformaciones en las condiciones contextuales de los territorios, los sujetos y las organizaciones que se ven inmersos en la práctica investigativa.

En concordancia con lo anterior, el desarrollo de la investigación y análisis de la información se abordó desde el método dialógico-conversacional, entendido como un campo de reflexión y acción en el que interactúan los sujetos a partir de la palabra compartida y el reconocimiento del otro (Freire, 2005). Busca la reivindicación del lugar de enunciación de los sujetos, de los espacios-tiempos vitales como colocación simbólica y material de los agentes a través de la experiencia, del lenguaje y de la reflexión intencionada y consciente (Ghiso y Tabares-Ochoa, 2011; Ghiso, 2017). La práctica social, la vida cotidiana y las interrelaciones subjetivas son constituyentes de una episteme dialógica solidaria. Esta episteme es una forma de conocer solidariamente, que se desarrolla en la práctica y atiende al reconocimiento de los sujetos en su historicidad, singularidad y capacidad de pronunciar el mundo (Ghiso, 2017).

Lo dialógico es un ámbito de encuentro e interacción de sujetos que se reconocen desde su campo experiencial, las tensiones, los encuentros y desencuentros (Ghiso y Tabares-Ochoa, 2011). No se da en condiciones neutrales ni de asepsia del pensamiento. "En el proceso dialógico se amplia y cualifica la comprensión de cómo los sentidos y los significados son construcciones producto de interacciones dadas en tiempos, espacios y escenarios que los condicionan" (Ghiso, 2001, p. 7). Lo dialógico es praxis para la reflexión crítica y producción de conocimientos desde diferentes lugares de significación. Es antagónico a la dualidad entre el conocimiento científico y el saber común (Santos, 2003; Torres, 2008). En este sentido, lo dialógico genera un desplazamiento de la centralidad del conocimiento como depósito y autoridad que invalida prácticas y conocimientos que no se producen desde los cánones racionales modernos.

La conversación, "más que una técnica de entrevista, (...) se asume como un marco social de interacción y de acercamiento a la complejidad de la historia y del mundo de hombres y mujeres" (Quijano, 2016, p. 39). La interacción se da en un marco de confianza como posibilitador de intercambios, aprendizajes, códigos, visiones y sistemas de representación condicionados por el contexto epistémico y experiencial de los sujetos. Conversar es la acción de la palabra en movimiento; es la posibilidad de estar siendo y de ser otros; es la construcción de una relación discursiva tejida desde la intersubjetividad, la pregunta y el espacio histórico. Para Quijano (2016), la conversación: 
...no solo tiene que ver con el intercambio verbal sino también con el acercamiento a la comprensión del universo simbólico, sensorial, espiritual, corporal, relacional y material donde importan tanto los datos discursivos como los argumentos, comentarios, narraciones, gestos, risas, tensiones, sueños, enojos, sentimientos, afectos, esperanzas, apuestas y luchas ontológicas. (p. 40)

Lo dialógico-conversacional, como método de investigación, converge en un espacio abierto y dinámico de construcción de conocimiento, pero también permite la reafirmación de los sujetos, sus prácticas, conocimientos y lugares de enunciación. Se entiende, entonces, desde las dimensiones de lo existente y de la potencia. De acuerdo con Ghiso (2017), "la construcción dialógica y solidaria de conocimiento es una experiencia de conciencia e imaginación que rompe con el interés hegemónico de negar, silenciar y neutralizar todo intento que surge desde la autonomía” (p. 258).

En esta misma línea, Quijano (2016) señala que "la conversación en tanto investigación compartida se presenta como forma de relacionamiento desjerarquizada que rompe con la asimetría convencional propia de los agentes o de las partes que movilizan el pensamiento desde espacios y posiciones monoculturales, universales y monológicas" (p. 39). Lo dialógico-conversacional se propone desde la ruptura con los marcos establecidos de producción de conocimiento y de la práctica de investigación soportada en la racionalidad cartesiana de aprehensión de la realidad desde puntos neutrales y objetivos, por fuera de la interacción de los sujetos y sus prácticas en un contexto epistémico.

\section{II.II. El camino metodológico}

Con el propósito de proponer la contabilidad popular como alternativa sociopráxica para la resignificación de las prácticas contables en las organizaciones de economía solidaria, se realizó un reconocimiento contextual y análisis de las dificultades y necesidades contables de 12 organizaciones de economía solidaria de las FARC-EP, que hacen parte del proceso de reincorporación económica colectiva promovida por Ecomún. Dentro de las organizaciones se encuentran cooperativas, corporaciones y asociaciones, ubicadas en los ETCR y NPR, de los departamentos de Chocó, La Guajira, Cesar, Cauca y Bolívar.

Para el desarrollo de la investigación se partió de una estrategia procesal para cada uno de los objetivos específicos (tabla 1), orientada, a su vez, por las categorías de análisis previas determinadas a partir de los objetivos y el problema de investigación. Estas categorías fueron: economía solidaria, organizaciones de economía solidaria, dificultades y necesidades contables de las organizaciones de economía solidaria y contabilidad popular. Las categorías emergentes también definieron el diseño de la estrategia metodológica, entre las que se encuentran Economías Sociales del Común, contabilidad financiera y educación popular. 
Gallón, N., Gómez, Y. y Rodríguez, M. Contabilidad popular. Una alternativa socio-práxica...

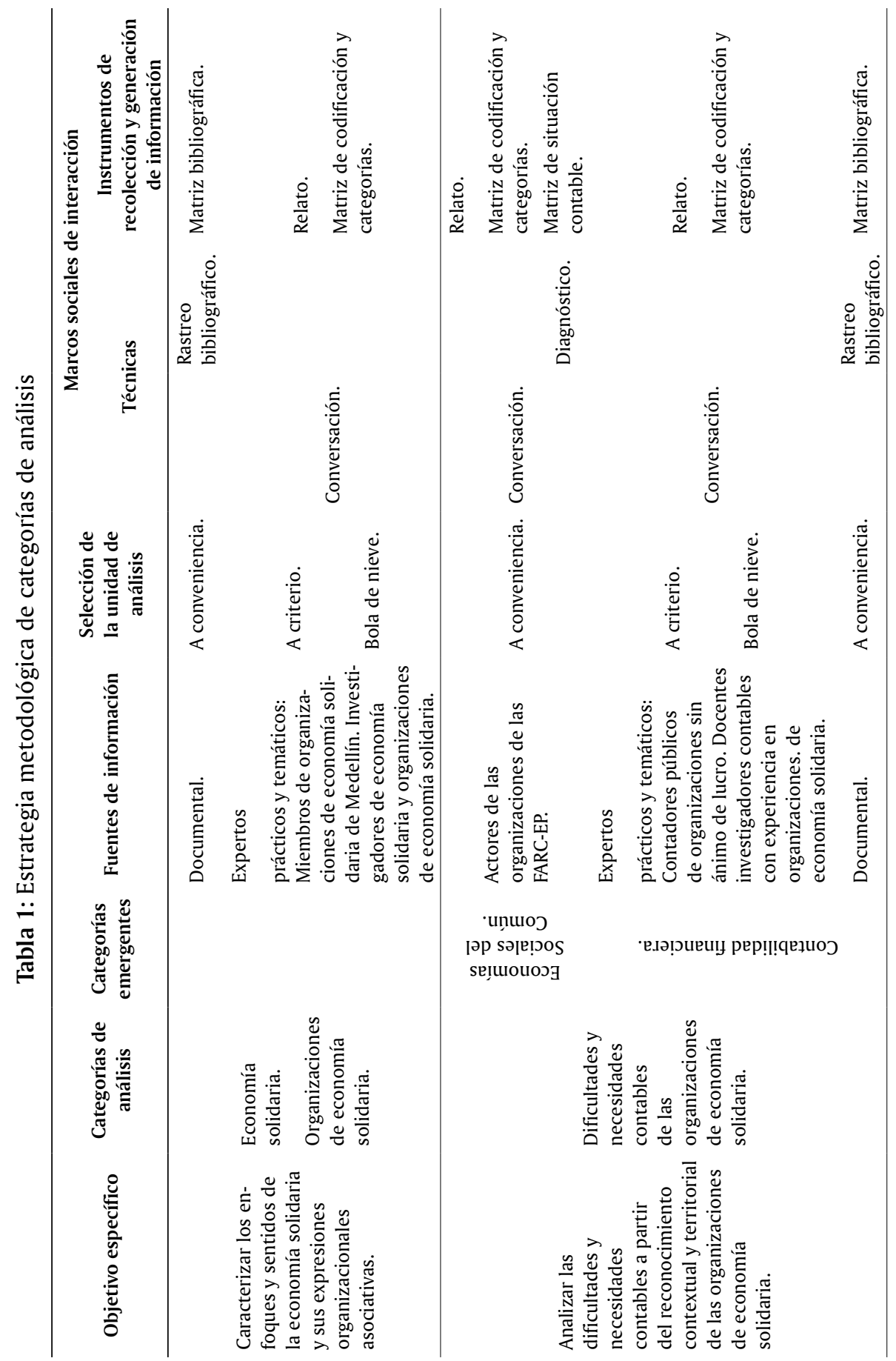




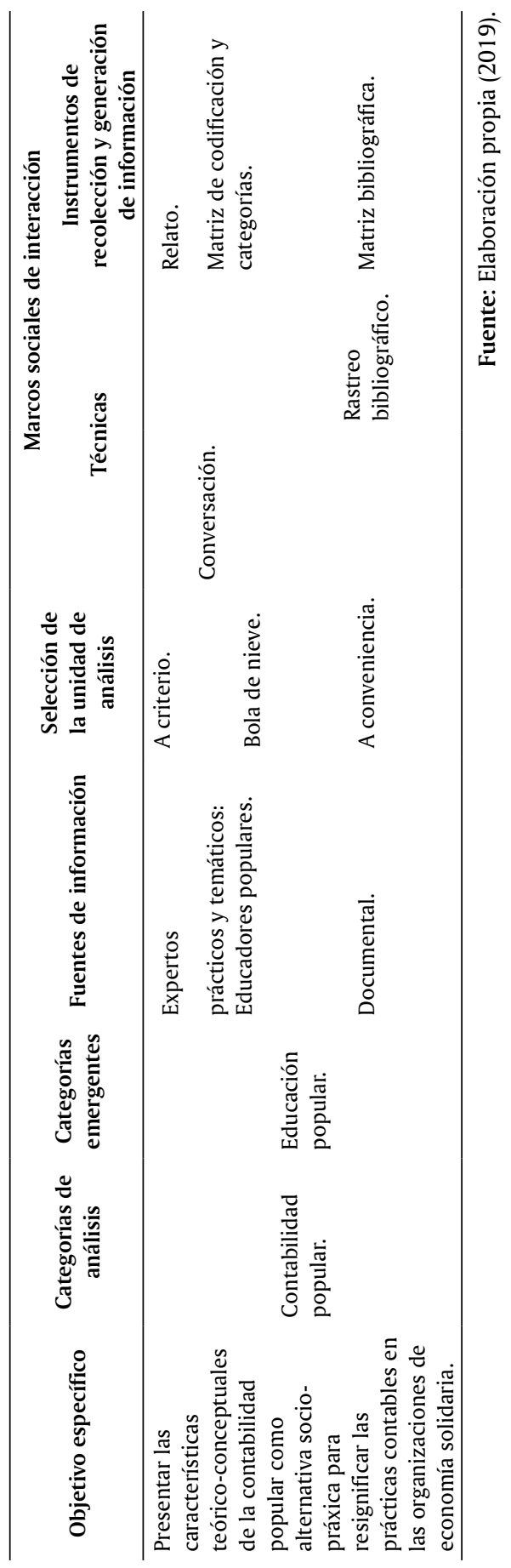

Contaduría Universidad de Antioquia - No. 77. Medellín, julio-diciembre 2020 
Gallón, N., Gómez, Y. y Rodríguez, M. Contabilidad popular. Una alternativa socio-práxica...

Por otro lado, las fuentes de información fueron documentales y orales. Las fuentes documentales fueron libros y artículos de revistas académicas, seleccionados de acuerdo con las categorías previas y emergentes. Por su parte, en las fuentes orales se definieron expertos prácticos y temáticos que respondieron a las categorías previas y emergentes. En ese sentido, se conversó con miembros de organizaciones de economía solidaria de Medellín, investigadores de economía solidaria y organizaciones de economía solidaria, contadores públicos de organizaciones sin ánimo de lucro, docentes investigadores contables con experiencia en organizaciones de economía solidaria, educadores populares y actores de las organizaciones de las FARC-EP. Si bien muchos de los expertos se identificaron de manera previa, otros emergieron, de acuerdo con el método de selección de la unidad de análisis.

El criterio de selección de los expertos prácticos y temáticos se definió por su experiencia, liderazgo comunitario y organizativo o trayectoria académica e investigativa en la economía solidaria, organizaciones de economía solidaria, Ecomún y educación popular. Fue muy importante contar con dos mujeres líderes de procesos comunitarios que hacen parte de corporaciones de economía solidaria (Fomentamos y Corporación Ecológica y Cultural Penca de Sábila) reconocidas en la cuidad por la defensa de la dignificación de la vida y las comunidades en los territorios desde apuestas como los Círculos Solidarios, donde emerge la categoría contabilidad popular, y la agroecología. Por otra parte, para conocer el contexto del proceso de reincorporación de las FARC-EP, el papel de Ecomún e identificar las dificultades y necesidades contables de las organizaciones de economía solidaria de los excombatientes, se conversó con la persona de Ecomún que acompaña actualmente el proceso jurídico de las organizaciones. Con el propósito de comprender algunas características de la educación popular, se sostuvo un encuentro con un líder de procesos de educación popular en diferentes espacios comunitarios y organizaciones educativas de la ciudad de Medellín.

Tabla 2: Expertos prácticos y temáticos

\begin{tabular}{|c|c|c|}
\hline Categorías & $\begin{array}{l}\text { Expertos prácticos } \\
\text { y temáticos }\end{array}$ & Caracterización \\
\hline \multirow{4}{*}{$\begin{array}{l}\text { - Economía solidaria. } \\
\text { - Organizaciones de } \\
\text { economía solidaria. }\end{array}$} & Ana Galeano. & $\begin{array}{l}\text { Líder comunitaria y organizativa, Directora } \\
\text { administrativa de la Corporación Fomentamos y los } \\
\text { Círculos Solidarios. }\end{array}$ \\
\hline & Claudia Cadavid. & $\begin{array}{l}\text { Líder comunitaria e integrante de la Corporación } \\
\text { Ecológica y Cultural Penca de Sábila. }\end{array}$ \\
\hline & Julián Vélez. & $\begin{array}{l}\text { Docente e integrante del Grupo de Investigaciones } \\
\text { Económicas, de la Universidad Autónoma } \\
\text { Latinoamericana. Línea de investigación economía } \\
\text { solidaria y campesina. }\end{array}$ \\
\hline & Hernando Zabala. & $\begin{array}{l}\text { Docente e integrante del Grupo de Investigación } \\
\text { de Economía Solidaria - Ecosol, de la Universidad } \\
\text { Católica Luis Amigó. }\end{array}$ \\
\hline
\end{tabular}




\begin{tabular}{|c|c|c|}
\hline Categorías & $\begin{array}{l}\text { Expertos prácticos } \\
\text { y temáticos }\end{array}$ & Caracterización \\
\hline \multirow[t]{2}{*}{$\begin{array}{l}\text { - Ecomún. } \\
\text { - Dificultades y } \\
\text { necesidades contables } \\
\text { de las organizaciones de } \\
\text { economía solidaria de las } \\
\text { FARC-EP. }\end{array}$} & Santiago Ramírez. & $\begin{array}{l}\text { Asesor jurídico de Ecomún y de las organizaciones } \\
\text { de los reincorporados de las FARC-EP. Además, es } \\
\text { asociado a una cooperativa de base de Ecomún. }\end{array}$ \\
\hline & Elkin Quirós. & $\begin{array}{l}\text { Docente universitario, cuyo trabajo investigativo } \\
\text { reciente se ha enfocado en organizaciones } \\
\text { agroecológicas de la ciudad. }\end{array}$ \\
\hline $\begin{array}{l}\text { - Dificultades y } \\
\text { necesidades contables } \\
\text { de las organizaciones de } \\
\text { economía solidaria. }\end{array}$ & Juan David Cardona. & $\begin{array}{l}\text { Docente universitario e integrante del grupo } \\
\text { RedComún, el cual ha acompañado diferentes } \\
\text { procesos en las organizaciones de los ETCR de } \\
\text { Antioquia. }\end{array}$ \\
\hline \multirow[t]{2}{*}{-Contabilidad financiera. } & Willinthon Osorio. & $\begin{array}{l}\text { Docente universitario y contador público de } \\
\text { organizaciones sin ánimo de lucro. }\end{array}$ \\
\hline & Willington Luján. & $\begin{array}{l}\text { Contador público con experiencia en organizaciones } \\
\text { sin ánimo de lucro. }\end{array}$ \\
\hline - Educación popular. & Fredy Vélez. & $\begin{array}{l}\text { Líder de procesos de educación y pedagogía } \\
\text { popular en diferentes organizaciones educativas y } \\
\text { comunitarias de la ciudad. }\end{array}$ \\
\hline
\end{tabular}

Fuente: Elaboración propia (2019).

En los marcos sociales de interacción se trabajó la conversación con expertos prácticos y temáticos como elemento que atraviesa la estrategia metodológica. La potencialidad de los marcos sociales de interacción reside en la interacción, dialogicidad y protagonismo de los sujetos en la reflexión crítica, comprensión y construcción de conocimiento y sentidos, a partir del reconocimiento de sus saberes, prácticas y experiencias propias que, en últimas, redunda en un posicionamiento epistémico y político de los sujetos en el desarrollo de la investigación. Como instrumento de recolección y generación de información se utilizó el relato y la matriz de codificación y categorías. Por otro lado, se utilizó el rastreo bibliográfico para las fuentes documentales y se construyeron matrices de codificación y categorías. Para identificar las dificultades y necesidades contables de las organizaciones de economía solidaria de los excombatientes de las FARC-EP, se aplicó un diagnóstico de situación contable.

El análisis y comprensión de la información y el desarrollo de las categorías previas y emergentes, se realizó a partir del cruce de las técnicas diseñadas para cada categoría, buscando relaciones, intersecciones y divergencias, más que contrastar o validar la información generada. Para su desarrollo, y como se expresó antes, fueron fundamentales las matrices bibliográficas, de codificación y categorización y de situación contable. 
Gallón, N., Gómez, Y. y Rodríguez, M. Contabilidad popular. Una alternativa socio-práxica...

\section{II.III. Los cambios en la estrategia metodológica}

El devenir de la investigación, las condiciones y emergencias del contexto de las organizaciones de economía solidaria de los excombatientes de las FARC-EP generaron cambios en la estrategia metodológica inicialmente planteada (tabla 3). Desde el enfoque de esta investigación, los ajustes que se realizaron no se interpretan como un desfase del alcance de la estrategia metodológica inicial. La lectura y reflexión que se hace está orientada a la comprensión de la realidad desde su complejidad, tensiones y singularidades que, en muchas ocasiones, no responden a las intencionalidades y voluntad de los sujetos o de las organizaciones; más bien hacen parte de condiciones coyunturales e históricas del proceso de reincorporación económica de las FARC-EP y el desarrollo de sus organizaciones.

Narrar y sistematizar los cambios y variaciones de la estrategia metodológica, presentados durante el desarrollo de la investigación, permite comprender lo metodológico "como una práctica flexible, frente a la racionalidad instrumental de la investigación que privilegia diseños rígidos, estrategias y técnicas estandarizadas" (Torres, 2014, p. 76). Es decir, lo metodológico es permeable, se va haciendo y transformando de acuerdo con las emergencias, realidades y sentidos de los sujetos y organizaciones que participan en la investigación.

A continuación, se describen los cambios realizados en la estrategia metodológica inicial.

Los objetivos específicos. En la estrategia metodológica inicial se había propuesto identificar las prácticas contables y explicar sus alcances y limitaciones en las organizaciones de economía solidaria. Por motivos de seguridad y logística, no fue posible viajar a los ETCR y NPR para trabajar con las organizaciones, lo cual obligó a cambiar estos dos objetivos por uno que buscara identificar las dificultades y necesidades contables; replanteando, también, las categorías de análisis, las fuentes de información, los marcos sociales de interacción y los instrumentos de recolección de información.

Las categorías de análisis. El cambio en dos de los objetivos específicos inicialmente planteados, conllevó a redefinir la categoría de análisis de acuerdo con el nuevo objetivo. De ahí entonces que ya no se buscó desarrollar la categoría de prácticas contables situadas, sino, dificultades y necesidades contables.

Las fuentes de información. Se delimitaron los actores de las organizaciones de economía solidaria de los excombatientes de las FARC-EP, pues ya no iba a ser posible el encuentro y conversación con los miembros de cada organización. Así que por facilidades en la comunicación se definió a la persona de Ecomún que está a cargo del acompañamiento jurídico, administrativo y contable de todas las organizaciones. Con el propósito de triangular la información y categorías de análisis predefinidas y emergentes, se buscaron contadores públicos como expertos prácticos y temáticos que tuvieran experiencia académica y profesional con organizaciones de economía solidaria. 


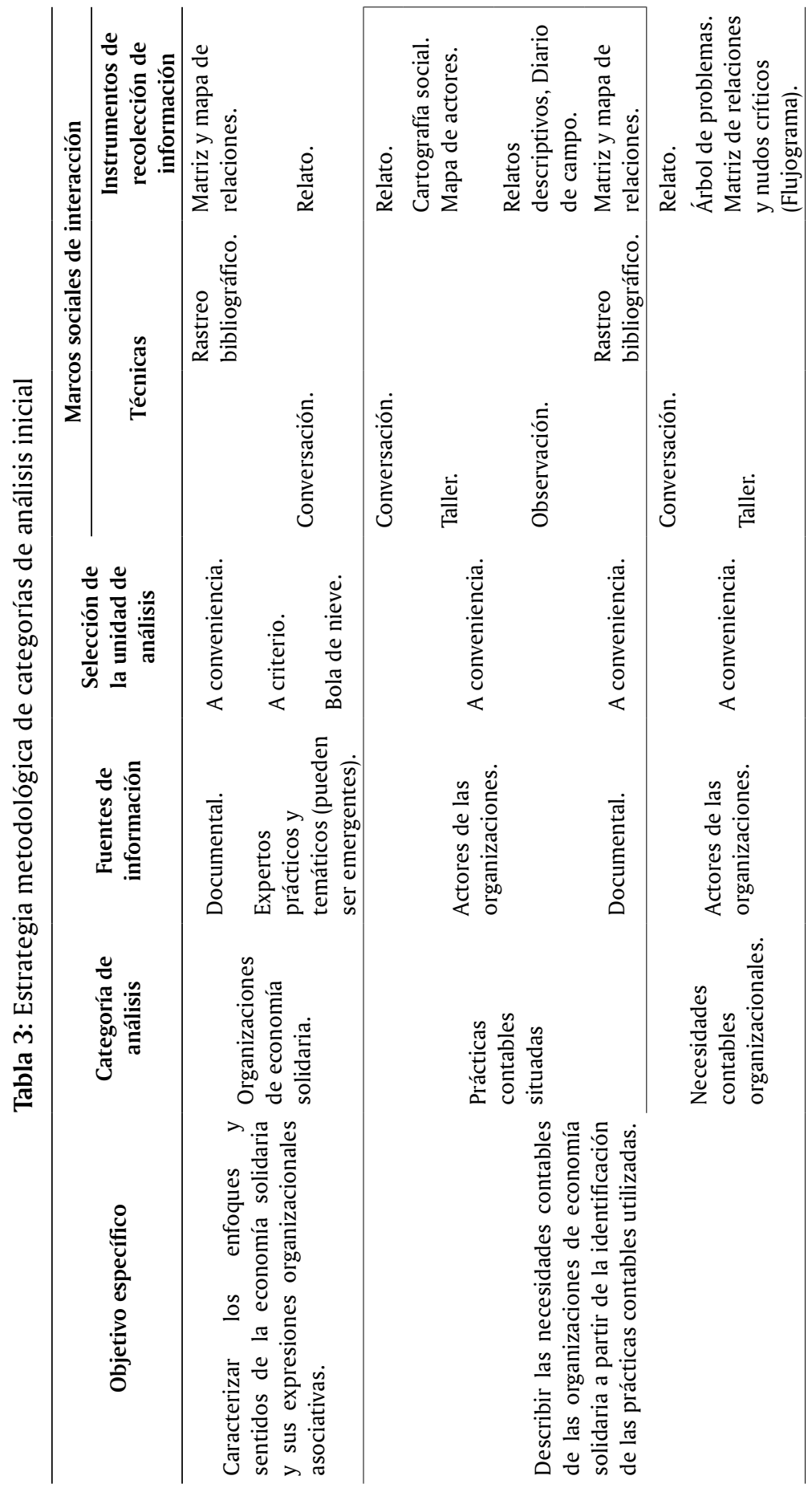


Gallón, N., Gómez, Y. y Rodríguez, M. Contabilidad popular. Una alternativa socio-práxica...

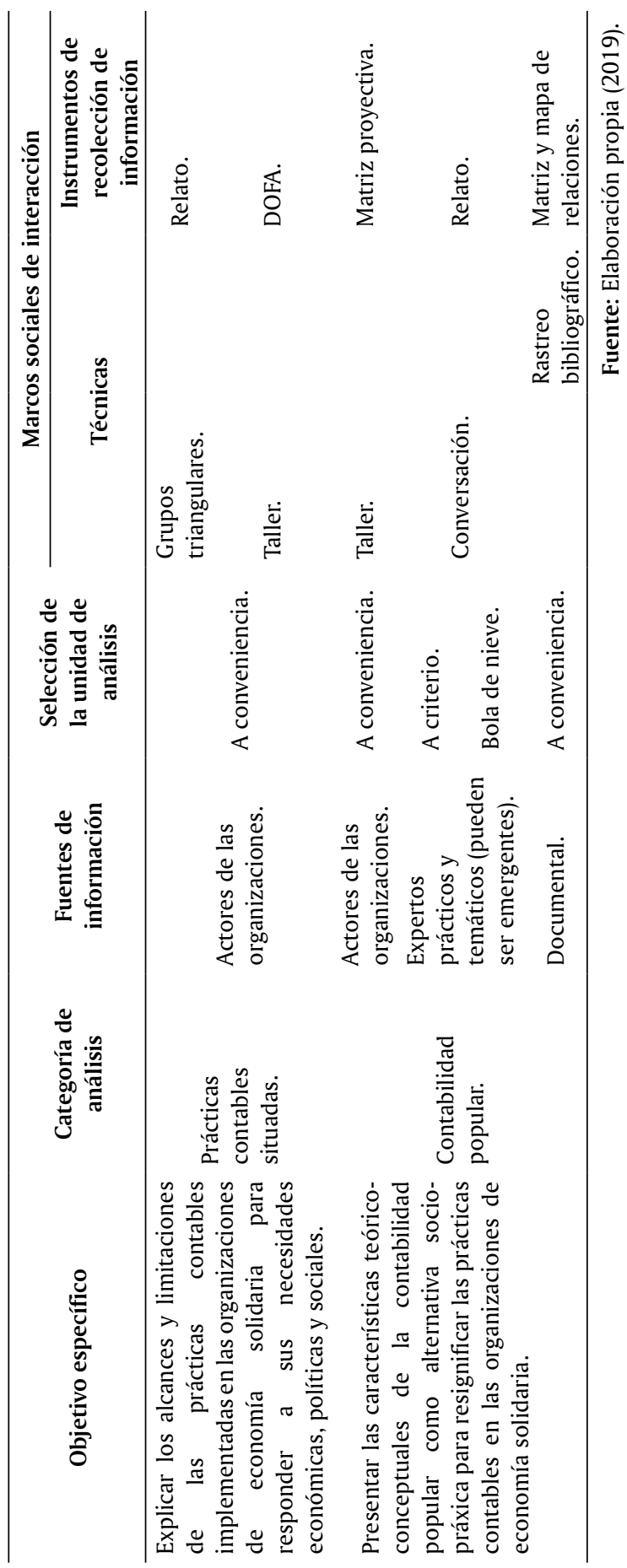


Los marcos sociales de interacción e instrumentos de recolección de información. Los cambios anteriores conllevaron a modificar los marcos sociales de interacción y sus respectivos instrumentos, dejando la conversación como marco central para el encuentro con los expertos prácticos y temáticos, y el análisis del relato y matriz de codificación y categorías como instrumentos para procesar la información. Para el nuevo objetivo analizar las necesidades y dificultades contables de las organizaciones de economía solidaria de los excombatientes de las FARC-EP se aplicó un diagnóstico, con el fin identificar la situación contable de las organizaciones.

La práctica investigativa permitió analizar y triangular la información para desarrollar cada uno de los objetivos. El siguiente capítulo presenta una caracterización de los sentidos y enfoques de la economía solidaria y sus organizaciones asociativas, en la que se ofrece una mirada más desde lo teórico y práctico que desde lo legal.

\section{Economía solidaria: caracterización y sentidos de lo solidario}

Las organizaciones de economía solidaria hacen parte de un conjunto de alternativas asociativas de formas sociales de producción, distribución y consumo, y de expresiones políticas y culturales, que nacen no solo como respuesta a las condiciones de pobreza, exclusión, desigualdad social y a la violencia estructural del capitalismo como proyecto económico y civilizatorio, sino también como formas genuinas, contrarias y antagónicas al capitalismo, como caminos para la construcción de otra economía y organización social. En Latinoamérica y Europa las organizaciones de economía solidaria han tenido una gran expansión, principalmente el cooperativismo como figura asociativa protagónica (Singer, 2011).

La economía solidaria es una nueva racionalidad económica que introduce la solidaridad como valor, práctica y vector en el ciclo económico y en las relaciones sociales para la apropiación colectiva de la producción, redistribución y de los escenarios participativos de decisión y gestión. Para Razeto (1997) la situación de pobreza y marginalidad de gran parte de los sectores sociales es una primera condición para hablar de economía solidaria, pues la solidaridad es connatural a la cultura de los grupos más pobres y excluidos. De ahí, entonces, que un camino que conduce a la economía solidaria es la economía popular (Razeto, 1997).

La economía popular se basa en el trabajo por cuenta propia de unidades familiares o pequeñas asociaciones de grupos sociales de una comunidad que "buscan resolver problemas mediante la ayuda mutua y el autodesarrollo. Implican relaciones y valores solidarios, pues el logro de los objetivos depende en gran medida del grado de cooperación, confianza y comunidad que alcancen sus integrantes" (Razeto, 1994, p. 16). El trabajo, lo comunitario y la autogestión 
Gallón, N., Gómez, Y. y Rodríguez, M. Contabilidad popular. Una alternativa socio-práxica...

son factores constitutivos de la economía solidaria, lo cual crea una distancia con las empresas capitalistas al redefinir la organización social y económica con fines colectivos y orientada a satisfacer las necesidades básicas y a la dignificación de los integrantes, en oposición a las relaciones de explotación y lógicas de acumulación del capitalismo (Razeto, 1994; 1997).

Para Coraggio (2011) la economía solidaria no puede estar por fuera de lo social, lo político y lo cultural, de ahí que la nombra como economía social y solidaria. En su desarrollo comprende dos dimensiones: las prácticas del trabajo mercantil autogestionado y del trabajo de unidades domésticas y comunidades mediante la producción de valores de uso y prácticas de supervivencia.

A diferencia de Razeto (1997), para Coraggio (2007) la solidaridad no es propia ni natural de los grupos más pobres y de las economías populares, así como tampoco implica igualdad y equidad per se. La solidaridad implica:

...reglas aceptadas de distribución y arreglos de reciprocidad de algún tipo, donde recibir obliga a retribuir de algún modo, establecido por usos y costumbres, a quien dio o al grupo al que pertenece el dador o a algún otro miembro de la comunidad. (p. 103)

Lo solidario, mas no necesariamente la economía solidaria, está presente en la economía pública a través del presupuesto participativo y la redistribución progresiva; en la economía de empresa capitalista, manifestada en prácticas filantrópicas y en la responsabilidad social; y en la economía popular a partir de la acción colectiva para mejorar las condiciones de vida de sus integrantes (Coraggio, 2013).

Con el propósito de delimitar un radio de acción y ejes teóricos de comprensión de la economía solidaria, Coraggio $(2011 ; 2013)$ presenta tres corrientes. La integracionista o de reinserción; la cual busca la integración social y reducir las condiciones de pobreza de las personas excluidas del mercado de trabajo, a través de la creación de emprendimientos en dirección de autoempleo y gestionados por los mismos propietarios bajo lógicas y prácticas capitalistas. Una segunda corriente es la de coexistencia y busca la creación de un sistema orgánico de economía social y solidaria paralelo a la economía capitalista, pero diferenciado en sus prácticas, medios y propósitos. Se caracteriza por la conformación de redes económicas, sociales y políticas, y por la reciprocidad a partir de la cooperación y la autogestión promovida por acciones colectivas. Por último, la construcción de otra economía, lo cual implica la transformación de las condiciones estructurales del capitalismo, dando origen a nuevas racionalidades, prácticas y modos de vida, producción económica y relaciones sociales y políticas.

Siguiendo una línea que, de acuerdo con lo anterior, podría inscribirse en una corriente de coexistencia, para Singer (2011) la economía solidaria es una alternativa conformada por y para los trabajadores excluidos y en condiciones de pobreza, que: 
...constituye un modo de producción que, junto con otros modos, (...) componen la formación social capitalista, pues el capitalismo no sólo es el modo de producción predominante, sino que adapta la superestructura legal e institucional de acuerdo con sus valores e intereses. (p. 66)

No obstante, el capitalismo no puede comprenderse como determinante y absolutista, pues dentro de él emergen otras opciones potenciales, que son reales y generan cambios en los sujetos y en las organizaciones sociales, económicas y políticas.

La economía solidaria integra la propiedad y apropiación de los medios de producción y distribución con la socialización de esos medios y lo hace a partir de una de sus figuras básicas más representativas, la cooperativa, en la que los trabajadores son los propietarios y su finalidad no es el lucro, sino maximizar las condiciones de los trabajadores y socios. El cooperativismo como eje organizativo esencial de la economía solidaria es, por lo tanto, colectivo, autogestionario y está soportado en la unidad entre trabajo y capital (Singer, 2007; 2011).

La economía solidaria no se limita solo a la acción de los trabajadores como actores y articuladores protagónicos, como lo plantea Singer (2007; 2011). Como escenario económico y social, en la economía solidaria participan diversos actores como trabajadores, consumidores y ciudadanos, asociados de manera voluntaria e involucrados en la búsqueda de fines comunes y movilizados por la acción solidaria como factor determinante para la preservación del vínculo social y colectivo (Gaiger, 2012; 2015).

Lo comunitario es una dimensión de la economía solidaria, que no solo toma un sentido de lo social y económico, sino que también está orientado a lo político como praxis constitutiva de un nosotros, de lo común y de la participación en escenarios de interés público con movimientos sociales, sindicales, rurales y ecológicos (Gaiger, 2012). La economía solidaria está inserta en un todo articulado y sistémico, de ahí que su alcance y efectos van más allá de una organización económica de autogestión, reciprocidad y cooperación en función de un bienestar colectivo y satisfacción de necesidades humanas, pues irradian otras esferas de lo social y político, para generar un cambio social (Guerra, 2010).

A partir de lo anterior, puede colegirse que la economía solidaria es una alternativa, entre muchas otras, que surge y coexiste con el capitalismo, pero se distancia de las relaciones de competencia, individualismo, explotación a partir del trabajo asalariado, y de la privatización de los medios de producción y de la riqueza, a partir de racionalidades, prácticas y valores que ponen el acento en la organización colectiva, la autogestión, la unión entre trabajo y medios de producción, y la necesidad y conciencia de cambio social y transformación de las relaciones económicas de corte capitalista. 
Gallón, N., Gómez, Y. y Rodríguez, M. Contabilidad popular. Una alternativa socio-práxica...

El componente axiológico de este tipo de economía redefine el sentido del qué, cómo y para qué de una unidad económica y asociación colectiva (Guerra, 2014). Lo solidario cobra una relevancia especial al anteponer la horizontalidad en las relaciones humanas, la ayuda mutua y el reconocimiento del otro como igual sobre el egoísmo, la caridad, la compasión y la filantropía (valores propios del cristianismo y del capitalismo). Lo solidario es una práctica, es acción social y política. Para Ana Galeano lo solidario es:

...la ayuda con los otros y para los otros. Dignificar al otro; trabajar en comunidad, en confianza, en recuperación de sus derechos. Es la dignificación de ellos [los sujetos] como personas. Dignificarse ellos como sujetos, como actores. Dignificar la vida en los territorios. Solidaridad es ayudar, acompañar, fortalecer. (Comunicación personal, 2019)

La economía solidaria debe entenderse de manera sistémica, pues no se trata de adjetivar la economía, donde lo solidario es un valor agregado de las prácticas económicas —-solidaridad en la economía - (Guerra, 2010). Si bien algunas de las organizaciones enmarcadas en esta economía surgen desde y para grupos en condición de pobreza, desempleo, violencia, ausencia de Estado, conflictos territoriales y ambientales, lo solidario y la conciencia de lo colectivo no es inmanente a estos grupos, de ahí que sea necesaria la acción, la conciencia y lo pedagógico como movilizadores de los sujetos; es decir, organización y formación son elementos importantes en la consolidación de una cultura, un movimiento y un sector de la economía solidaria.

El proceso productivo de la economía solidaria está conformado por cinco momentos, según Coraggio (2016):

La producción racional de bienes y servicios, (...) cuyo sentido de realización de las capacidades humanas del trabajo es resaltado: antes que una economía del capital que se autoreproduce, se trata de una economía del trabajo que reproduce la vida. La distribución y redistribución de la nueva riqueza producida (y del patrimonio acumulado), entendida esta como valores de uso útiles para realizar las necesidades de todas y todos. El intercambio justo entre personas, sectores y regiones -con predominio de la reciprocidad por sobre la competencia. Los modos de consumo responsable con la naturaleza y la convivencia social. (pp. 18-19)

El proceso económico está orientado a satisfacer las necesidades humanas y mejorar y/o mantener unas condiciones de vida digna. La eficiencia y sostenibilidad son redefinidos, pues no se buscan en sentido financiero y de rendimientos monetarios, sino en el impacto de la calidad de vida de los sujetos en los territorios, en las redes de colaboración solidaria, en los fines colectivos, comunitarios, culturales y principios éticos (Gaiger, 2007; Coraggio, 2011).

Existe una amplia variedad de formas de organización de economía solidaria (cooperativas, unidades de economía popular, emprendimientos familiares o comunitarios, asociaciones, corporaciones, mutualidades, entre otras) creadas 
de manera jurídica; no obstante, "no es la figura jurídica de la entidad que se crea la que importa y donde está la relación con la economía social y solidaria" (Julián Vélez, comunicación personal, 2019). De ahí que se pone el acento en lo sustantivo sobre la forma; es decir, la economía solidaria como práctica más que como figura legal (Guerra, 2010).

La autogestión es, tal vez, una de las características más representativas e interesantes de la economía solidaria que, aunque se puede encontrar en otras formas de organización social y económica, constituye una esfera de participación democrática, de responsabilidad y socialización del curso de la organización de manera colectiva. No se trata tanto de la autogestión en el sentido de la capacidad individual, es decir, del autogobierno, que parte del trabajo como factor productivo para emprender, sino como capacidad y proceso de los sujetos para organizarse y gobernarse a partir del trabajo y el factor comunitario (Guerra, 2013; Razeto, 1994). Se trata de construir una identidad colectiva y la autogestión se encamina hacia ese sentido, pero, más aún, a la autodeterminación de las comunidades sobre su territorio y la manera de conformar procesos económicos, políticos y sociales.

\section{La contabilidad en las organizaciones de economía solidaria: una mirada contextual}

Este capítulo desarrolla un análisis de las dificultades y necesidades contables de las organizaciones de economía solidaria de los excombatientes de las FARC-EP, desde el reconocimiento de su contexto y territorialidad. El capítulo está dividido en tres partes. La primera pone en contexto la conformación de las organizaciones de economía solidaria de las FARC-EP, las cuales surgen en el proceso de reincorporación económica colectiva, promovido por Ecomún, organización que nace con el Acuerdo final para la terminación del conflicto y la construcción de una paz estable y duradera, firmado entre el Gobierno Nacional y las FARC-EP en 2016. La segunda parte analiza las dificultades y necesidades contables de las organizaciones de economía solidaria de las FARC-EP. Por último, como categoría emergente, se presenta un análisis del sentido y limitaciones de la contabilidad financiera en las organizaciones de economía solidaria.

\section{IV.I. Economías Sociales del Común}

El Acuerdo final para la terminación del conflicto y la construcción de una paz estable y duradera, firmado entre el Gobierno Nacional y las FARC-EP en 2016, está compuesto por seis acuerdos que trazan las bases, orientaciones y medidas para la construcción de paz desde un enfoque territorial, de género y étnico: Hacia un nuevo campo colombiano: Reforma rural integral, Participación en 
Gallón, N., Gómez, Y. y Rodríguez, M. Contabilidad popular. Una alternativa socio-práxica...

política, Fin del conflicto, Solución al problema de las drogas ilícitas, Víctimas del conflicto armado e Implementación, verificación y refrendación.

El acuerdo tres, Fin del conflicto, contiene, entre otros puntos, la Reincorporación de las FARC-EP a la vida civil en lo económico, lo social y lo político. El proceso de reincorporación está "orientado al fortalecimiento del tejido social en los territorios, a la convivencia y la reconciliación entre quienes los habitan; asimismo, al despliegue y el desarrollo de la actividad productiva y de la democracia local" (Alto Comisionado para la Paz, 2016, p. 69). Ecomún nace de este acuerdo como organización de economía social y solidaria, con el propósito de promover el proceso de reincorporación económica colectiva e individual de los excombatientes de las FARC-EP. El Decreto Ley 899 de 2017 presenta los criterios e instrumentos para la reincorporación económica y social colectiva de las FARC-EP; en ese sentido, autoriza y le da carácter de obligatoriedad a la constitución de Ecomún como organización especial de economía social y solidaria.

Otro instrumento jurídico que le da respaldo al proceso de reincorporación es La Política Nacional para la Reincorporación Social y Económica de exintegrantes de las FARC-EP (Conpes 3931 de 2018), el cual tiene entre sus objetivos generar las condiciones para el acceso a mecanismos y recursos necesarios para la estabilización y proyección económica de los exintegrantes de las FARC-EP y sus familias. La estrategia está orientada al acompañamiento para el fomento de alternativas productivas, colectivas e individuales para la consolidación de fuentes de ingresos, de acuerdo con la vocación de los territorios, usos del suelo, generación de dinámicas productivas sostenibles y restaurativas, necesidades del contexto e intereses de los reincorporados; es decir, se busca desarrollar la proyección económica de acuerdo con un enfoque territorial, para lo cual son necesarias acciones interinstitucionales y rutas de atención en torno al fomento y fortalecimiento de formas asociativas, entre ellas Ecomún, de las FARC-EP (Conpes, 2018).

Ecomún se constituye formalmente en 2017 como una cooperativa para ser el organismo paraguas que cobije todo el proceso de reincorporación económica y social, a partir de la apuesta por la economía social y solidaria como alternativa y la organización y fortalecimiento colectivo y político de los reincorporados. En términos formales, actualmente, ${ }^{4}$ está conformada por 40 personas naturales, de los cuales 26 son delegados de los Espacios Territoriales de Capacitación y Reincorporación (ETCR), y las demás personas

4 En 2020 busca constituirse como una cooperativa de segundo nivel, a partir del asocio de cooperativas y otras figuras de organización social y solidaria, para fortalecer y desarrollar estrategias para segmentos productivos y de servicios de las iniciativas de los reincorporados: vivienda, turismo, caficultura, confecciones y piscicultura (Santiago Ramírez, comunicación personal, 2019). 
naturales se asociaron con posterioridad, entre las que se incluyen personas que no ostentan la calidad de exguerrilleras; sin embargo, en el proceso de reincorporación se han asociado 110 organizaciones de economía solidaria y se empezará con el proceso paulatino en el que las personas naturales solicitan no continuar asociadas para que Ecomún esté conformado solo por personas jurídicas y continúe el proceso de transformación en organización de segundo nivel. En términos de lo que representa, Ecomún son todas y todos los exintegrantes de las FARC-EP que están en el proceso de reincorporación (Santiago Ramírez, comunicación personal, 2019).

El acompañamiento que realiza Ecomún a las figuras asociativas (cooperativas, corporaciones, asociaciones) de los reincorporados se hace en varios frentes: economía del cuidado y género, acceso a tierras, diseño y ejecución de proyectos productivos y legalización (lo concerniente a lo administrativo, contable y jurídico). Este proceso lo hace con financiación de cooperantes internacionales y articulación con instituciones.

Los proyectos productivos pueden ser individuales y colectivos, pero la apuesta es por lo colectivo, de acuerdo con el espíritu del proceso de reincorporación. Hasta el momento, de los 29 proyectos productivos presentados para evaluación y aprobación del Consejo Nacional de Reincorporación (CNR), solo se han desembolsado recursos para 18 proyectos; no obstante, varias de las iniciativas productivas se han podido ejecutar y consolidar con recursos propios de los reincorporados, la financiación de cooperación internacional, el apoyo de algunas empresas nacionales e instituciones territoriales. En las organizaciones no solo están asociados los exintegrantes de las FARC-EP de las ETCR y los NPR, también las integran personas de las comunidades (campesinos, comunidades indígenas, afrodescendientes, zonas de reserva campesina) (Santiago Ramírez, comunicación personal, 2019).

El desarrollo de proyectos productivos bajo el esquema asociativo de la economía solidaria representa no solo una forma de reincorporación económica y colectiva, también es una reincorporación comunitaria de las FARC-EP en los territorios, que permite construir lazos de convivencia, confianza y reconstrucción del tejido social. La apuesta por la construcción de paz con enfoque territorial pasa por la autonomía y autodeterminación de los pueblos, de ahí que el fortalecimiento de lo comunitario, las relaciones de economía basadas en la economía solidaria y la organización social y política de quienes hacen parte de los territorios deben ser parte de la agenda y sentido de la reincorporación.

En el proceso de reincorporación de las FARC-EP, desde la constitución de las cooperativas hasta la aprobación y ejecución de los proyectos productivos, se han presentado dificultades que han hecho que se entorpezca y se desvíe 
Gallón, N., Gómez, Y. y Rodríguez, M. Contabilidad popular. Una alternativa socio-práxica...

el sentido del proceso de reincorporación económica colectiva. La mayoría de los proyectos responden a la vocación y cultura agrícola de los territorios; sin embargo, el acceso a la tierra para el trabajo y desarrollo de las actividades económicas es uno de los aspectos más críticos (Santiago Ramírez, comunicación personal, 2019; Conpes, 2018; Llorente y Méndez, 2019), pues el Gobierno Nacional no ha implementado los mecanismos para el uso y tenencia de la tierra para los reincorporados. El acceso a la tierra para los proyectos ha sido vía arrendamiento, lo cual sigue reproduciendo un modelo de tenencia concentrada de la tierra parecido al feudalismo, lo que mantiene y agudiza una de las causas estructurales de la violencia y el conflicto armado en el país (Santiago Ramírez, comunicación personal, 2019).

Otros aspectos están relacionados con el incumplimiento del Gobierno de implementar el Acuerdo Final, la violencia en los territorios y el asesinato de los exguerrilleros, la débil articulación y presencia institucional en los territorios, así como el desarrollo de estrategias integrales en los territorios desde una apuesta social y económica, tanto en beneficio de las FARC-EP como de las comunidades de los territorios. Según el diagnóstico presentado por el Conpes:

Existen dificultades en la reconstrucción del tejido social, la convivencia, la reconciliación, la seguridad y el acceso a la oferta institucional para la reincorporación comunitaria en los territorios, (...) riesgos de seguridad que enfrentan las comunidades, organizaciones sociales y exintegrantes de las FARC-EP en las zonas donde se desarrolla la reincorporación. (2018, p. 46)

También dificultades relacionadas con la formalización y constitución legal de las cooperativas, la gestión y lo contable, la formulación y viabilidad financiera de los proyectos, y el débil acompañamiento técnico y formación en el campo de la economía solidaria (Santiago Ramírez, comunicación personal, 2019; Martínez y Lefrebvre, 2019).

\section{IV.II. Dificultades y necesidades contables de las organizaciones de economía solidaria}

Como se señaló en el apartado anterior, una de las estrategias para la reincorporación económica y social de las FARC-EP es la constitución de figuras asociativas para el desarrollo de proyectos productivos desde la economía solidaria. Las cooperativas, asociaciones y corporaciones resultan de la integración, no solo de los reincorporados, sino también de sus familias y de algunas personas que hacen parte de la comunidad donde está situado el ETCR y el NPR. Buscan resolver las necesidades de los asociados y de la comunidad en general; de ahí que las organizaciones están pensadas también en función de construir confianza y procesos de reconciliación con la comunidad que habita el territorio.

Con el propósito de identificar las dificultades y necesidades contables, se tomaron 12 organizaciones (cooperativas, asociaciones, corporaciones) de los 
exintegrantes de las FARC-EP, ubicados en los ETCR y NPR de los departamentos de Chocó, La Guajira, Cesar, Cauca y Bolívar. La conformación de las organizaciones de los reincorporados que han optado por la vía colectiva ha respondido a las dinámicas del contexto de los territorios; en ese sentido, su proceso no ha sido homogéneo. No obstante, al menos en las organizaciones que aquí se analizan, se encuentran aspectos comunes. En términos generales, las principales dificultades están relacionadas con el proceso de constitución y formalización legal, lo contable y tributario de las organizaciones una vez formalizadas, el seguimiento financiero de los proyectos y el poco acompañamiento técnico y de formación en economía solidaria y contabilidad. Las necesidades responden a la construcción y apropiación de conocimientos, procesos y prácticas contables, en particular del presupuesto, asignación de costos, y de la gobernabilidad de las organizaciones; es decir, de la gestión y control.

La constitución y formalización legal de las figuras asociativas ha sido un proceso lento y truncado por varios factores. El primero de ellos es la bancarización de los reincorporados. En reiteradas ocasiones ha sido negada la apertura de una cuenta bancaria, obligando a los exintegrantes de las FACREP a poner un derecho de petición. La cuenta bancaria es indispensable para el desembolso de la renta básica mensual y el apoyo económico, otorgado por única vez para los proyectos productivos. Por otro lado, la elaboración de los estatutos, actas y conformación del Consejo de Administración ha requerido acompañamiento, así como la contratación de servicios contables para la elaboración del balance de apertura. El registro en la Cámara de Comercio ha sido complejo por el diligenciamiento de los formatos. La Superintendencia de la Economía Solidaria, ante la radicación de los documentos, ha hecho varias sugerencias sobre actas y estatutos, en su función de control de legalidad. En cuanto a la Dirección de Impuestos y Aduanas Nacionales (DIAN), más que una dificultad, se presenta es una necesidad de solicitar la autorización para facturación y la firma digital.

Al poner en contexto las dificultades relacionadas con la formalización de las organizaciones es posible, de entrada, afirmar que es normal que este tipo de situaciones se presenten y a las que se tienen que enfrentar todas las organizaciones, pero no es así. Si bien son procedimientos institucionalizados, no son asimilados por igual, porque hay unas barreras de acceso y unas prácticas y contextos que condicionan las relaciones de los sujetos con las instituciones y los procesos burocráticos.

Los excombatientes de las FARC-EP estuvieron por fuera del conjunto de valores, prácticas, instituciones y comportamientos sociales y políticos aceptados y legítimos, entre ellos el Estado y el modelo económico vigentes. De ahí que parte de su proceso de reincorporación sea justamente integrarse, hacer parte del entramado institucional, legal y legítimo que ordenan la vida, 
Gallón, N., Gómez, Y. y Rodríguez, M. Contabilidad popular. Una alternativa socio-práxica...

las relaciones, el ejercicio del poder y el comportamiento de los sujetos en el Estado colombiano. Ahora, con esto no se quiere decir que haya un proceso de acoplamiento, adaptación y aceptación acrítico y sin resistencia, pero en el caso particular de la constitución legal, desarrollo y consolidación de las organizaciones hay un acuerdo de hacerlo bajo las condiciones legales y conforme a la política de economía solidaria y de sus formas asociativas que establece el Estado (Alto Comisionado para la Paz, 2016).

Otras de las razones de la situación que se ha presentado con la constitución legal de las organizaciones, tiene que ver con el incumplimiento del Gobierno y su débil capacidad de respuesta y atención a las necesidades de las figuras asociativas. Por otro lado, "Ecomún, después de un año de haberse constituido como organización formal, empezó a tener apoyo de cooperación internacional, y solo hasta ese momento pudo acompañar los procesos en los territorios" (Santiago Ramírez, comunicación personal, 2019).

Un segundo aspecto que se ha presentado en el desarrollo de las organizaciones, y en el que se ha venido trabajando de manera paulatina en medio de las dificultades, es lo concerniente al proceso contable, tributario y a la figura de tesorería de las organizaciones una vez formalizadas; de igual manera, también hace referencia al seguimiento financiero y administrativo de los proyectos productivos. Hasta el momento, las figuras asociativas tienen unas necesidades urgentes que las han llevado a concentrarse en la dimensión legal de la contabilidad y en cumplir con las obligaciones tributarias.

En atención a esto, algunas organizaciones han contratado servicios contables temporales, de manera autónoma, para la elaboración y certificación de los estados financieros y declaración de renta, recurriendo a otras organizaciones que tienen presencia en el territorio y que prestan acompañamiento y asesoría contable. En otros casos, como el de la asociación y cooperativas del departamento de Sucre, el acompañamiento y capacitación por parte de la Agencia para la Reincorporación y la Normalización (ARN) generó acción con daño ${ }^{5}$. Por otra parte, la Unidad Administrativa de Economía y Organizaciones Solidarias (UAEOS) ha generado acciones en los territorios a partir de las capacitaciones en economía solidaria, pero lo ha hecho bajo un enfoque legal y fiscal, lo que no ha permitido la comprensión de una perspectiva más amplia de las organizaciones de economía solidaria (Santiago Ramírez, comunicación personal, 2019).

Ecomún, con el propósito de poner al día la contabilidad y la contabilidad fiscal de las organizaciones, y llevar un proceso de formación y construcción de

5 Las prácticas de la ARN han generado acción con daño en las organizaciones porque no ha habido un acompañamiento en la formulación de los proyectos productivos de los reincorporados de las FACR-EP, de acuerdo con el contexto y pertinencia del proyecto que se quiere proponer para los territorios y las comunidades. 
prácticas contables situadas, sostenido en el tiempo, a partir de una orientación pedagógica popular y de marcos sociales de interacción, se ha articulado con un equipo de trabajo de contadoras y contadores. Esta articulación ha contado con financiación de cooperación internacional y, a pesar de que ya quedó en firme, no se ha iniciado el acompañamiento en los territorios por razones de orden logístico y de seguridad.

En cuanto a los proyectos productivos, varias de las organizaciones han empezado a desarrollarlos, otras no porque los proyectos están represados para ser evaluados y aprobados por el CNR, o ya fueron aprobados, pero no se han desembolsado los recursos. Muchos de los proyectos con las últimas características han contado con cierre financiero, lo que les ha permitido ejecutar el proyecto. En otros casos han sido devueltos porque no cumplen los requisitos técnicos y de viabilidad y sostenibilidad financiera. En este sentido, una barrera que se ha presentado es, por un lado, el débil acompañamiento técnico para la formulación de los proyectos y construcción del marco financiero e indicadores de medición de resultados y, en segundo lugar, los proyectos que se encuentran en marcha requieren elementos y herramientas contables y de gestión, sobre todo en cuanto a planeación, presupuesto, costos y control.

El carácter colectivo y solidario de las organizaciones implica una designación de responsabilidades y la participación de los socios en las diferentes áreas: administrativa, contable y operacional. Un rasgo distintivo de este tipo de formas asociativas es la apropiación colectiva de las funciones, alcances e implicaciones de la organización en un sentido orgánico; por eso los roles se asumen de acuerdo con las capacidades, pero también hay una formación con el propósito de relevar a las personas al frente de cada responsabilidad. Todo esto para decir que no necesariamente se requiere una experticia o formación calificada para desempeñar funciones en las organizaciones; de ahí que algo que se presenta en las organizaciones de los reincorporados es la necesidad de formación en las funciones y responsabilidades del tesorero y la gobernabilidad, a partir del fortalecimiento organizativo y de la participación para la gestión y el control.

Dentro de las necesidades también emerge la construcción y apropiación de conocimientos, prácticas y técnicas contables. Esto resalta el carácter contextual de la contabilidad, al ser permeada y moldeada por las condiciones e intereses de las organizaciones y los sujetos. También deja ver una postura que deslinda de la concepción de la contabilidad que la afinca y absolutiza como una obligación legal y fiscal, para reafirmar el poder que ella tiene en el funcionamiento, medición, organización, control y gobernabilidad de las unidades productivas y las personas. La necesidad de apropiación es un elemento clave para comprender el sentido y finalidades de las prácticas 
Gallón, N., Gómez, Y. y Rodríguez, M. Contabilidad popular. Una alternativa socio-práxica...

contables en este tipo de organizaciones, pues se manifiesta como un asunto de responsabilidad colectiva, que pasa por la conciencia y experiencia de los miembros de la organización.

Como se expresó antes, muchas de las organizaciones han contratado servicios contables para fines específicos, lo que se limita a un acompañamiento externo de personas que no conocen la organización, que no construyen con sus miembros y que se dedican a preparar y certificar la información contable; lo que está bien porque se ajusta a la norma y, en ese sentido, las organizaciones cumplen con el reporte de estados financieros certificados, pero se queda en el campo que reproduce la contabilidad desde la dimensión legalista y financiera (Gómez y Ospina, 2009; Gómez, 2019). Dimensión que es importante y necesaria en las organizaciones de economía solidaria; sin embargo, deja por fuera necesidades y realidades que escapan a ese campo.

La comprensión del sentido de las dificultades y necesidades contables de las organizaciones de economía solidaria de los reincorporados de las FARC-EP no puede hacerse por fuera de su contexto histórico. Implica reconocer los lugares y condiciones en los que se ha desarrollado su práctica vivencial. Comprender el contexto es, en parte, asignarle sentido a la práctica. Los excombatientes de las FARC-EP son campesinos, que gran parte de su vida estuvo relacionada con el conflicto armado y político. De ahí que parte de su proceso de reincorporación sea un tránsito a integrarse y relacionarse con los códigos, valores, comportamientos y figuras institucionales que se consideran legítimas para regular la vida y relaciones sociales por fuera de la guerra. Tener una cédula, una cuenta bancaria y constituir una unidad productiva bajo los marcos legales e institucionales representa un cambio de vida y nuevas condiciones para comprenderse y desarrollarse como sujetos que ya no hacen parte de la guerra, pero que emprenden un cambio que aún está marcado por sus vivencias en ella; es decir, hay una memoria de lo que representa su paso por las FARC-EP y convicciones políticas que se mantienen y trazan gran parte de su comportamiento, forma de pensar y de organizarse política y económicamente.

Desde su experiencia y práctica, los excombatientes de las FARC-EP no han tenido relación ni conocimiento con los conceptos y prácticas contables, porque su vivencia cotidiana y circunstancias han sido otras y no han tenido la necesidad ni han estado bajo condiciones que requieran tener un manejo de lo contable. Desde el contexto de los excombatientes de las FARC-EP se comprenden las dificultades y necesidades contables que se les han presentado con la constitución y desarrollo de las organizaciones de economía solidaria, lo que, justamente, hace parte también de su proceso de reincorporación, en el que se generan las condiciones y necesidades de lo contable para sus unidades productivas. 
Si bien las organizaciones de economía solidaria se estructuran y devienen de acuerdo con el contexto, su relación con el territorio, las tensiones y conflictos dentro y fuera ella, también comparten elementos comunes que coinciden con los lineamientos institucionales de formalización, control y vigilancia, y con la regulación contable y fiscal, lo que, para Ana Galeano, Claudia Cadavid y Julián Vélez (comunicación personal, 2019) se convierte en un obstáculo, condiciona su autonomía, moldea, adapta y asimila la organización a una empresa de capital privado, haciendo que, en muchos casos, se transforme o desaparezca.

La situación de las organizaciones de economía solidaria deja ver un desfase entre el sentido de la economía solidaria y las instituciones que las regulan. Así entonces, "Las prácticas y necesidades de las organizaciones no compaginan con las prácticas institucionales” (Julián Vélez, comunicación personal, 2019). Esto puede entenderse como una forma en la que el capitalismo también opera e incide en este tipo de organizaciones que se inscriben en una economía alternativa. Para Juan David Cardona (comunicación personal, 2019) "El capitalismo tiene una maleabilidad que da cabida a procesos alternativos, pero que son cooptados".

Las organizaciones de economía solidaria, de acuerdo con Gaiger (2007), están inmersas en las lógicas y principios de la economía capitalista. Las reglas del mercado e intercambio son adaptadas para cumplir con los estándares de eficiencia, crecimiento y sostenibilidad con los que son medidas. Este es un punto clave en la comprensión de las organizaciones de economía solidaria y la adaptación de la base técnica del capitalismo y la participación en las relaciones de mercado, pues si bien la economía solidaria no logra transformar ni proponerse como modelo de producción antagónico al capitalismo, sí permite poner en el centro lo colectivo como fuerza para trabajar y mejorar las condiciones de vida de los sujetos; es decir, tiene unos fines que escapan a las lógicas del capitalismo.

Se busca asimilar las organizaciones de economía solidaria a las empresas de capital privado, desconociendo su racionalidad económica, los contextos y finalidades sociales y políticas para las que se crean y, en esa misma medida, los índices de eficiencia, rentabilidad y sostenibilidad son aplicados bajo los criterios del capital financiero (Coraggio, 2011). En este sentido, se adopta el modelo y prácticas contables financieras, porque permite institucionalizar y legitimar las organizaciones de economía solidaria y medir el nivel de cumplimiento de los principios capitalistas. De esta manera, ¿Cuál es el sentido de la contabilidad financiera en las organizaciones de economía solidaria? ¿Qué tipo de realidad representa? ¿Cuáles son sus limitaciones teniendo en cuenta que los fines de las organizaciones de economía solidaria no son de acumulación y competencia? 
Gallón, N., Gómez, Y. y Rodríguez, M. Contabilidad popular. Una alternativa socio-práxica...

\section{IV.III. El sentido de la contabilidad financiera en las organizaciones de economía solidaria}

Con la pretensión de homogeneizar y representar fielmente la realidad económica y financiera con el fin de que la información sea útil para la toma de decisiones, la contabilidad financiera no hace distinciones sobre el tipo, contextos y finalidades de las organizaciones (Gómez, 2019). El enfoque legal y financiero de la contabilidad que prevalece en las organizaciones de economía solidaria, no busca tanto permitir lenguajes y representaciones de relaciones económicas colectivas y solidarias, en cambio sí medir e informar sobre la eficiencia y sostenibilidad económica como vectores, a su vez, de la eficacia administrativa y de la legitimidad del sector en la economía.

Cabe aclarar que el problema no es la eficiencia y sostenibilidad económica, pues se consideran de vital importancia para el desarrollo y la toma de decisiones de las organizaciones; el planteamiento va encaminado a que, en gran medida, la racionalidad de la contabilidad financiera se soporta en postulados que se distancian de las necesidades y propósitos de las organizaciones de economía solidaria, y parte de su instrumental contable es insuficiente para la autogestión de las mismas. Desde luego, la contabilidad financiera también ofrece prácticas e instrumentos que son pertinentes y necesarios para las organizaciones de economía solidaria y no se puede afirmar que habría que suprimirla; lo que se busca es reconocer sus limitaciones en la autogestión, control, toma de decisiones y fines políticos y comunitarios de las organizaciones, y la necesidad de que haya una resignificación para que sean apropiadas de manera colectiva por los agentes que hacen parte de las organizaciones.

Para Willinthon Osorio (Comunicación personal, 2019) la contabilidad financiera, bajo estándares internacionales, "no consulta los intereses de las organizaciones de economía solidaria; consulta los intereses de los accionistas, entonces, ¿qué pasa con los intereses de las organizaciones donde es más importante el interés de impactar una población que de generar utilidades?" El sentido de la contabilidad financiera es calcular, medir y representar relaciones económicas y financieras basadas en la acumulación, la competencia y el crecimiento ilimitado (Martínez, 2014; Gómez, 2005), propio de la empresa de capital privado, pero que no son principios de las organizaciones de economía solidaria, pues si bien algunas de ellas ${ }^{6}$ basan sus relaciones comerciales y de intercambio en el mercado, bajo lógicas capitalistas, sus fines están orientados a la supervivencia, el desarrollo y dignificación de los territorios y de las comunidades, o a la producción de bienes materiales a partir de relaciones

6 Otras organizaciones realizan sus intercambios en circuitos de colaboración solidaria o comercio justo. 
colectivas y solidarias. Lo que marca un carácter contrario, en otros casos alejado de la racionalidad capitalista y del homo economicus. En este sentido, para Elkin Quirós:

Todo modelo contable desarrolla una forma de representación que responde al concepto de mantenimiento del capital, el cual está alejado de una organización de economía solidaria. La contabilidad financiera solo ve una forma de capital, la financiera. Otras formas de capital no entran ahí, como lo social o lo relacional. El modelo es incapaz de ver eso, porque el concepto de capital a mantener es el financiero, y otras formas de capital no las va a ver ni las va a considerar como representaciones legítimas. (Comunicación personal, 2019)

El profesor Elkin Quirós señala un aspecto importante para la comprensión del sentido de la contabilidad financiera en las organizaciones de economía solidaria y es la representación. Bajo el modelo de contabilidad financiera, y siendo una característica cualitativa fundamental de la información financiera útil, se busca la representación fiel de la realidad (NIIF, 2018). Esto quiere decir que la contabilidad representa la realidad tal cual es y de manera neutral. En consecuencia, la contabilidad es una "métrica isomorfa de la realidad" (Gómez, 2011, p. 131) que guarda correspondencia con el paradigma de la utilidad al buscar disminuir la incertidumbre en la toma de decisiones (Jiménez y Mora, 2012).

Desde el enfoque dominante, la realidad que representa la contabilidad es la financiera y la estructura y criterios de medición e información están soportados en la racionalidad del control y crecimiento del capital de los inversores. La contabilidad reduce la realidad a lo financiero bajo unas condiciones de economía capitalista, pero al ser aplicada en organizaciones de economía solidaria deja por fuera las relaciones colectivas y solidarias de producción, en las que la propiedad, el control de la propiedad, la gestión de los recursos, la toma de decisiones y los fines que busca deslindan de la lógica de la contabilidad financiera, o en otros casos, resulta ser insuficiente. Por otro lado, para las organizaciones de economía solidaria "la contabilidad es una obligación asimilada al pago de impuestos" (Willington Luján, comunicación personal, 2019). De ahí, entonces, que lo contable representa tres grandes dificultades para este tipo de organizaciones.

La primera, la contabilidad se presenta como un obstáculo bajo el modelo financiero al estar condicionada por la regulación contable internacional y los propósitos de homogeneización y al desvincularse de las realidades no financieras de las organizaciones de economía solidaria. Por otro lado, la contabilidad, en mayor medida, se relaciona con el control fiscal y el pago de cargas tributarias. En tercer lugar, las prácticas y técnicas estandarizadas de la contabilidad, así como los medios de representación e información, difícilmente logran ser apropiados por los miembros de las organizaciones y, gran parte de estos, son limitados e insuficientes para la autogestión, control, representación 
Gallón, N., Gómez, Y. y Rodríguez, M. Contabilidad popular. Una alternativa socio-práxica...

y construcción de las realidades sociales y económicas, la sostenibilidad, eficacia social y la toma de decisiones.

Las organizaciones de economía solidaria tienen unas necesidades contables específicas, sobre todo prácticas contables que respondan a sus contextos y lógicas organizativas. Como lo expresa el profesor Elkin Quirós "las finalidades de las organizaciones de economía solidaria, y el control al logro de esas finalidades, podría indicar que se necesitan mensajes y representaciones diferentes. A lo mejor se necesita adaptar o crear herramientas contables para eso" (Comunicación personal, 2019).

Se hace necesario volver la mirada, aguda y crítica, sobre la pertinencia del conocimiento y práctica contable, en particular, en el contexto de las organizaciones de economía solidaria, como formas asociativas de una alternativa económica y social. De igual manera, cabe indagar por el papel de la contabilidad en la construcción y consolidación de esa alternativa que hoy hace parte de la estrategia de reincorporación económica de las FARC-EP. Así, cabe preguntarse: ¿Cuál es la contribución de la contabilidad en esta apuesta económica y política de construcción de paz con enfoque territorial? ¿De qué manera vincular la academia y comunidad contable con las organizaciones para construir prácticas y formas de representación alternativas? En este punto se concuerda con el profesor Juan David Cardona cuando afirma que:

...cómo construir con las comunidades unas necesidades de información a partir de lo que necesitan reconocer de los recursos, los procesos sociales y económicos, y encontrar unas formas en las cuales se dé cuenta de esas realidades y en ese sentido ellos puedan tomar decisiones con base en las realidades propias de la comunidad. (Comunicación personal, 2019)

Pensar en alternativas contables implica un giro epistemológico y metodológico; una apertura a contextos con unas necesidades particulares que exigen prácticas contables situadas que den sentido, nombren y transformen esas realidades. El desfase entre la capacidad de respuesta y pertinencia de las prácticas y racionalidad del modelo contable financiero, y los contextos, dificultades y necesidades contables de las organizaciones de economía solidaria debe conllevar a la reconfiguración y transformación de las relaciones con las organizaciones al reconocerlas como campos económicos, políticos y de producción de conocimientos. Podría ser necesario repensar el vínculo e intervención de los contadores públicos en las organizaciones de economía solidaria, pues su práctica no diferencia el tipo de organización y no da cabida a construir relaciones y conocimientos con los actores de las organizaciones, sino que deposita prácticas y metodologías estandarizadas, lo que, parafraseando a Freire (2005), podría considerarse una concepción bancaria de la práctica contable en las organizaciones de economía solidaria. 


\section{Contabilidad popular: aproximaciones teórico-conceptuales}

Pensar la contabilidad popular nos invita a trazar un horizonte de sentidos y posibilidades marcado por la experiencia, la práctica contextuada y un posicionamiento epistémico y ético-político frente a la realidad. Aproximarnos a la categoría de contabilidad popular conlleva a asumir una relación del pensamiento con la realidad, como una forma de colocarse frente a las circunstancias que se quieren conocer (Zemelman, 2005). Esta relación, la forma de pensar la realidad, puede ser desde un pensamiento teórico, es decir, "un pensamiento de contenidos, que hace afirmaciones sobre la realidad" o a partir de un pensamiento epistémico, que parte de la pregunta como manera de "colocarse frente a las circunstancias sin anticipar ninguna propiedad sobre ellas" (Zemelman, 2005, p. 66).

El pensar epistémico representa un distanciamiento de la realidad, de las teorías y conceptos que utilizamos para comprenderla. La creencia ciega en la teoría, confiando en su significado claro y explicación de la realidad, conlleva a un desfase entre la realidad y la teoría, pues estamos construyendo conceptos sobre realidades inventadas. De ahí entonces la necesidad de pensar en contra de las propias verdades, certezas e inercias mentales y asumir una postura de apertura frente a lo desconocido, lo diverso y a las posibilidades de ser y comprender la realidad desde la imaginación, la capacidad de asombro y la duda. "El pensar epistémico consiste en el uso de instrumentos conceptuales que no tienen un contenido preciso, sino que son herramientas que permiten reconocer diversidades posibles de contenido" (Zemelman, 2005, p. 71).

La categoría de contabilidad popular nos permite colocarnos y dar cuenta de la realidad desde el pensamiento epistémico; de ahí que su corpus teórico y conceptual no sea definido, sino que se subordina a lo indeterminado de la realidad que busca comprender y explicar; es decir, hablamos de la pertinencia histórica del conocimiento y la necesidad constante de resignificación en un horizonte de posibilidades y un devenir abierto y construible (Zemelman, 1998; 2005). En ese sentido, las aproximaciones teóricas y conceptuales a la categoría contabilidad popular se hacen desde la sospecha y se presentan como instrumentos construibles a partir de las posibilidades de las experiencias y el desenvolvimiento de la realidad en el tiempo. Es decir, la contabilidad popular no tiene un contenido único y demarcado sino muchas posibilidades de contenido (Zemelman, 2005).

Un primer momento de aprehensión concreta y expresión de la contabilidad popular es en la práctica cotidiana de organizaciones de economía popular, particularmente, en los Círculos Solidarios de Medellín - Colombia. La contabilidad popular es una denominación de las prácticas contables que han desarrollado los Círculos Solidarios y que surgen de las necesidades de 
Gallón, N., Gómez, Y. y Rodríguez, M. Contabilidad popular. Una alternativa socio-práxica...

supervivencia de los sujetos y actores que allí participan, con el propósito de apropiarse, a partir de sus prácticas cotidianas, sociales y experienciales, de las dinámicas contables de su unidad productiva (Rodríguez, Gallón y Gómez, 2016; 2018). A partir de lo anterior, identificamos que la contabilidad popular es una práctica que se desarrolla como forma de apropiación de la contabilidad por parte de los sujetos en una organización que se enmarca en la economía alternativa.

Al ampliar el espectro de comprensión de la contabilidad popular, podemos decir que hace parte de un campo de reafirmación y de emergencias de realidades, prácticas, conocimientos, interexistencias, subjetividades, producción y resignificación de sentidos desde los lugares de enunciación y contextos vitales de los sujetos sociales organizados en una forma asociativa de economía solidaria.

La contabilidad popular, entonces, tiene una dimensión ontológica, cuya relación con la realidad no consiste en reducirla a lo que existe, sino que, justamente, es un campo de visibilidad y producción de realidades y prácticas contables otras. Y una dimensión epistemológica de los conocimientos y agentes ausentes y emergentes; es decir, la contabilidad popular, a partir de la rehabilitación del sentido común y de reconocer las prácticas sociales como prácticas de conocimiento (Santos, 2003; 2009; 2010), expande las posibilidades de la contabilidad en las organizaciones, de ahí que genera las condiciones para la emergencia de prácticas contables y formas de representación de la realidad. Pone el acento, además, en conocer creando solidaridad, "el momento del saber es la solidaridad, el reconocimiento del otro como igual e igualmente productor de conocimiento" (Santos, 2009, p. 86).

Los agentes ausentes y emergentes, bajo la perspectiva de Santos (2009), hacen referencia a la demanda de subjetividades y relaciones intersubjetivas que buscan romper las inercias y revitalizar la praxis para ser y conocer de y desde otros modos posibles y con los otros; a la capacidad de agencia y protagonismo de los sujetos en la producción y resignificación de prácticas y conocimientos contables desde sus realidades concretas y experiencias posibles.

La contabilidad popular, como alternativa socio-práxica para resignificar las prácticas contables en las organizaciones de economía solidaria, se alimenta de algunas de las asunciones y desarrollos teóricos de la contabilidad como práctica social e institucional. Desde esta postura se comprende que la contabilidad y las prácticas contables son intrínsecamente sociales, devienen de las relaciones sociales y son un territorio que constituye formas plurales y emergentes de representar, comprender la realidad y de visibilizar hechos, actividades, comportamientos y discursos, para procesarlos y actuar sobre ellos, a la vez que desarrolla una capacidad para cambiarlos (Miller y O'leary, 1987; Miller, 1994; Miller y Power, 2013). 
La contabilidad y las prácticas contables son una forma de intervención en el funcionamiento de las organizaciones y de la sociedad; en ese sentido, configuran expresiones que permiten priorizar posibilidades de acción y orientar las decisiones y comportamientos en función de la organización como parte de un entramado social y político (Potter, 2005). La contabilidad y las prácticas contables no solo se aplican a las actividades de las organizaciones, también son constitutivas de una territorialización; es decir, de espacios no solo físicos, sino también de relaciones sociales y económicas, que se demarcan para medir y evaluar el desempeño de la organización y controlar el comportamiento y resultados de los sujetos. Desde esta perspectiva, la contabilidad también es un proceso que incide y es constituyente de subjetividades. (Miller y Power, 2013).

Las organizaciones, la contabilidad y las prácticas no se desarrollan en un vacío o una independiente de la otra (Miller, 1994). Su interrelación e interacción posibilita un mapa de existencias, comportamientos, intereses, producción, reproducción y transformación de sentidos. Son dinámicas e históricas (Gómez, 2019); son forma y expresión de relaciones, condiciones y posibilidades que las delimitan y anclan a un espacio-tiempo, pero también permiten su transformación, devenir y resignificación. Para Gómez (2011) "la contabilidad evoluciona con las organizaciones. Este argumento, que la contabilidad evoluciona con las organizaciones, es vital para entender la dinámica contextual de la contabilidad" (p. 143).

A partir de lo anterior, en la interrelación entre organizaciones, contabilidad y prácticas, ¿desde qué lugar o lugares pensar esta relación en el campo de economías alternativas en las que se inscriben organizaciones con propósitos no capitalistas? ¿Es posible comprender las organizaciones solo como campos y desde su relación con lo social, lo económico, lo político y lo cultural? ¿Cuáles son los sentidos de la contabilidad y las prácticas contables en organizaciones donde se busca su apropiación por parte de los miembros, quienes, en muchos casos, no tienen formación en contabilidad? Si la contabilidad evoluciona con las organizaciones y responde a dinámicas contextuales: ¿Es posible pensarla sin la experiencia, la práctica, consciencia y voluntad de los sujetos que conforman las organizaciones? ¿Es un proceso despersonalizado, acéfalo? ¿Cuál es el papel de los sujetos en el desarrollo de la contabilidad en las organizaciones? ¿A partir de qué proceso o prácticas se podría pensar, construir y resignificar la contabilidad en las organizaciones? La respuesta podría estar en la contabilidad popular como posibilidad.

La contabilidad popular es una práctica pedagógico-política y social que busca reafirmar y resignificar los conocimientos y prácticas contables que las organizaciones desarrollan para responder a sus necesidades y generar las condiciones para la emergencia de otras prácticas contables situadas con las organizaciones de economía solidaria, desde la educación popular como acción 
pedagógica, ético-política y como praxis de transformación. Esta propuesta de contabilidad es popular porque es una práctica política que se potencia y materializa en la acción pedagógica como campo intencionado de colocación de los sujetos en un contexto histórico para ampliar sus posibilidades de acción y autonomía, a partir de la reflexión crítica de su experiencia y práctica situada, la organización económica, política y social, y el encuentro dialógico.

El sentido de resignificar se comprende desde el imperativo de un distanciamiento de las teorías, contenidos y prácticas que se han presentado como diáfanos, determinados y veraces para explicar y comprender una realidad en un momento socio-histórico dado, para buscar otras posibilidades de ámbitos de sentidos y nombrarlos desde categorías construibles, que se van transformando de acuerdo con las emergencias y las exigencias de las realidades históricas (Zemelman, 2005). Desde la contabilidad popular, resignificar las prácticas contables en las organizaciones de economía solidaria es un posicionamiento contextual de los sentidos y saberes ante las posibilidades de las emergencias, a partir de la reflexión crítica de la práctica. Implica un proceso de concienciación y subjetivación que permita movilizar a los sujetos hacia la búsqueda de nuevos campos de significación de su práctica para que sea pertinente y coherente con las necesidades contables de las organizaciones. La contabilidad popular resignifica la práctica contable porque le da valor y sentido en el contexto de las organizaciones de economía solidaria y de los sujetos como agentes históricos.

La contabilidad popular, entonces, tiene sentido y se fundamenta en la educación popular. No es posible desvincular el proceso de formación y pedagógico de la apuesta por otras prácticas contables, porque es a partir de la acción educativa y pedagógica, enmarcados en la educación popular, que se construyen nuevos conocimientos situados y se antepone al sujeto social como agente de conocimiento, reflexión, acción y transformación.

La educación popular "no es una disciplina, ni sólo un campo intelectual, sino una acción cultural y pedagógica comprometida, la preocupación no es exclusivamente epistemológica o teórica, sino eminentemente política y práctica” (Torres, 2010, p. 18). La educación popular es, en sí misma, política (Ghiso, 2009; Jara, 2018). Lo político como constitutivo y esencial de la educación popular no se entiende por fuera de la acción de los sujetos, el contexto de la práctica, los lugares de enunciación y significación y las voluntades, vínculos, afectos y concienciación como parte de un proceso de ser y estar en el mundo para transformarlo a partir de la transformación del mismo sujeto. La educación es una práctica situada; es decir, no se "puede dar independiente del vínculo con la realidad en la que está ubicado [el sujeto]" (Jara, 2018, p. 249). Se desarrolla y parte del contexto y práctica cotidiana como principio de conocimiento y reflexión, pero también como campo de acción político. 
Para Torres (2018) la educación popular no se limita "al plano de la conciencia, se ensancha al plano de la subjetividad, que en su dimensión individual y colectiva gobierna las lecturas de realidad, los procesos de construcción de identidad, los vínculos y las opciones y voluntades de acción" (p. 9). La subjetividad es un ámbito central de la educación popular porque es a partir de allí que se generan cambios en los modos de pensar y comportarse de los sujetos, de relacionarse con el mundo y con los otros. Son las vivencias y alteridades que pasan por el cuerpo y modifican o transforman los vínculos, racionalidades y permiten construir un posicionamiento histórico que redunda en la praxis para la emancipación y las posibilidades de conocer con otros desde lo dialógico, la solidaridad y la esperanza (Freire, 2012).

En la educación popular se pueden identificar tres grandes dimensiones y expresiones constitutivas que amplían los fundamentos y el sentido de la contabilidad popular: la práctica educativa y pedagógica, la praxis y la reflexión crítica de la práctica.

La práctica educativa y pedagógica. Parte de la ruptura con la educación bancaria; es decir, la educación como depósito en la que el sujeto queda reducido a objeto (Freire, 2005); por el contrario, se asume que "enseñar no es transferir conocimiento, sino crear las posibilidades para su producción o construcción" (Freire, 1997, p. 47). La contabilidad popular para resignificar las prácticas contables en las organizaciones de economía de solidaria asume que la práctica educativa y pedagógica parte del sujeto y su contexto histórico, atraviesa la experiencia para volver a ella con una mirada crítica para transformarla. El proceso de aprendizaje es práctico y reflexivo, y se genera en la interacción, el reconocimiento y respeto por los saberes de los otros. La producción de conocimiento no es un proceso aislado de la realidad, del sentido común, las experiencias colectivas y los entornos de las organizaciones; es un proceso que se da a través de la conversación y el diálogo como formas de conocer solidarias. "La solidaridad construye un nosotros pedagógico contextuado" (Ghiso, 2018, p. 212).

La praxis. Es acción y reflexión para transformar la realidad (Freire, 2005). La contabilidad popular parte de reconocer a los sujetos como partícipes de una comunidad, un colectivo, una organización, e implica reconocer su historicidad, singularidad y experiencias vitales como portadoras de conocimientos y partes de entretejidos subjetivos, porque no se trata tanto de una individualidad, como sí de una amalgama de voces que han incidido en su formación y en la forma de identificarse y saberse en el mundo. Como sujetos de la praxis estamos condicionados, pero no determinados (Freire, 1997); de ahí que nuestra práctica y contexto sea un campo de posibilidades, abierto a lo desconocido, en el que podemos incidir, recrear, imaginar y transformar. "Reconocernos condicionados y entender nuestras prácticas situadas en una historicidad 
Gallón, N., Gómez, Y. y Rodríguez, M. Contabilidad popular. Una alternativa socio-práxica...

comprendida como posibilidad, nos lleva a resituarnos como sujetos pertinentes de reflexión y de acción" (Ghiso, 2018, p. 200).

La reflexión crítica de la práctica. "La reflexión crítica sobre la práctica se torna una exigencia de la relación Teoría/Práctica sin la cual la teoría puede convertirse en palabrería y la práctica en activismo" (Freire, 1997, p. 24). La contabilidad popular, a partir de la práctica pedagógica, del encuentro educativo y del proceso dialógico, posibilita que los sujetos reflexionen la práctica contable en el marco de las organizaciones de economía solidaria. La reflexión crítica de la práctica contable en las organizaciones de economía solidaria no se da por inercia o imposición del conocimiento y práctica contable de expertos académicos y asesores contables, o desvinculada de las intencionalidades y necesidades de la autogestión de las organizaciones y las apuestas colectivas y comunitarias; por el contrario, implica un afloramiento de voluntades, de conciencia y un proceso intersubjetivo para propiciar un campo de encuentro de saberes; poner en duda las certezas y cuestionar el sentido y pertinencia de las prácticas contables. La concienciación, como condición de darse cuenta para actuar, se amplía para interactuar con los terrenos de la curiosidad epistémica y la subjetividad como proceso de apropiación de la práctica situada y su reflexión crítica.

A partir de lo anterior, la contabilidad popular en las organizaciones de economía solidaria de los excombatientes de las FARC-EP podría ser una posibilidad de comprensión y significación de las prácticas contables desde su contexto como campesinos y campesinas, que están en proceso de reincorporación a la vida social, política y económica bajo un Acuerdo Final, materializado en su voluntad de paz y marcado por propósitos de reconciliación y reconstrucción del tejido comunitario. Partir de reconocer su realidad contextual e histórica abre el camino para que la contabilidad popular, desde la educación popular y el encuentro dialógico y solidario, permita el reconocimiento e integración de la diversidad de saberes, la experiencia vital y la práctica contextuada para generar las condiciones de emergencia de prácticas contables, de reflexión crítica y de resignificación como procesos permanentes, de acuerdo con las dificultades, necesidades y fines de las organizaciones.

Las organizaciones de economía solidaria de los reincorporados de las FARC-EP son campos epistémicos y contextos de formación en sí mismos, pues las organizaciones, no solo de economía solidaria, también populares, artísticas y culturales, están aprendiendo y enseñando todo el tiempo; es decir, la vida cotidiana de las organizaciones es un espacio formativo (Torres, 2004) de intercambio de saberes, formas de ver el mundo, significarlo, de relacionamiento y de actuación de los sujetos. Los espacios de encuentro, de reflexión colectiva, de discusión y toma de decisiones sobre la autogestión de las organizaciones son vitales porque construyen vínculos, transforman, 
resignifican contextos colectivos y subjetivos y son generadores de nuevos saberes, conocimientos y prácticas como posibilidades de comprensión, pero, sobre todo, de identidad y de saberse parte de un nosotros político. Esto es fundamental para comprender la contabilidad popular en las organizaciones de economía solidaria, pues se parte de reconocer que las organizaciones no son entes ficticios, vacíos y estáticos, y los sujetos que hacen parte, no son depósitos receptores (Freire, 2005) de información de expertos que van a formarlos en contabilidad. De ahí que la contabilidad popular se fundamenta en la educación popular como praxis política y episteme dialógica solidaria (Ghiso, 2017).

La contabilidad popular debe comprenderse en relación con los procesos y fines organizativos y con los sujetos que hacen parte de la organización, su experiencia, práctica social y conocimientos propios. Estas relaciones deben estar atravesadas por la educación popular y lo pedagógico, porque es a partir de la formación de los sujetos, la praxis, la concienciación y la reflexión crítica de la práctica, que se crean las posibilidades de comprensión y resignificación de las prácticas y el sentido contable en las organizaciones. Es decir, es un proceso de subjetivación para la apropiación, empoderamiento y expansión de la pertinencia de las prácticas contables en las organizaciones de economía solidaria.

\section{VI.Conclusiones}

Las organizaciones de economía solidaria de los excombatientes de las FARC-EP tienen dificultades y necesidades contables que no se resuelven con la aplicación indistinta de prácticas contables bajo el modelo financiero o con la intervención de los contadores públicos bajo unos marcos de reproducción bancaria de la práctica contable, porque, justamente, en sí mismos representan un problema para las organizaciones. De ahí que acompañar, construir, pensar y trabajar con las organizaciones sea una de las apuestas de la contabilidad popular para el fortalecimiento de los procesos organizativos, la autogestión y el cumplimiento de sus objetivos económicos, políticos y colectivos.

La contabilidad popular como práctica pedagógico-política y social busca resignificar las prácticas contables en las organizaciones de economía solidaria desde la educación popular y la práctica pedagógica como ejes centrales para generar las condiciones que permitan reafirmar, resignificar y emerger nuevos conocimientos y prácticas contables, a partir de la experiencia subjetiva y colectiva, lo dialógico y lo solidario como formas de conocer y de relacionamiento. La educación popular es en sí misma política y sus intencionalidades se dirigen a la formación de los sujetos como agentes de la práctica educativa y pedagógica, la praxis y la reflexión crítica de la práctica, de ahí que la contabilidad popular sea, ante todo, una práctica que se va haciendo 
Gallón, N., Gómez, Y. y Rodríguez, M. Contabilidad popular. Una alternativa socio-práxica...

y transformando de acuerdo con los contextos, emergencias y necesidades de las organizaciones, y con los sentidos que los sujetos construyan en un campo epistémico y dialógico de saberes y experiencias vitales.

Las aproximaciones teórico-conceptuales a la categoría contabilidad popular se presentan como instrumentos construibles que dependen de las prácticas y del desarrollo de las realidades de las organizaciones de economía solidaria y los sujetos que las conforman; de ahí que quedan abiertas a las posibilidades de teorización y a la diversidad del conocimiento que se pueda llegar a construir con las organizaciones a partir de investigaciones situadas, participativas y emergentes. Las posibilidades de comprensión y desarrollo de la categoría contabilidad popular son tantas como las emergencias y condiciones sociohistóricas de las realidades y los contextos de las organizaciones de economía solidaria, pero es importante tener en cuenta que exige cambios en la forma de conocer, investigar y construir teoría, pues los referentes, aunque sean críticos, hacen parte de la tradición moderna y cuyo enfoque se aleja del contexto de las realidades emergentes. Esto, además, permitirá explorar la contabilidad popular en otro tipo de organizaciones y bajo otras condiciones contextuales.

\section{Referencias bibliográficas}

Alto Comisionado para la Paz. (2016). Acuerdo final para la terminación del conflicto y la construcción de una paz estable y duradera. Recuperado de: https:/www.jep.gov.co/ Marco\%20Normativo/Normativa_v2/01\%20ACUERDOS/N01.pdf

Coraggio, J. (2007). Una perspectiva alternativa para la economía social: De la economía popular a la economía del trabajo. En J. Coraggio, Economía social desde la periferia. Contribuciones latinoamericanas (pp. 165-194). Buenos Aires: Editorial Altamira.

Coraggio, J. (2011). Economía social y solidaria. El trabajo antes que el capital. Quito: Ediciones Abya-Yala.

Coraggio, J. (2013). Las tres corrientes de pensamiento y acción dentro del campo de la economía social y solidaria. R. B. Estudos Urbanos e Regionai, 15(2), 11-24. Doi: http:// dx.doi.org/10.22296/2317-1529.2013v15n2p11

Coraggio, J. (2016). La economía social y solidaria (ESS): niveles y alcances de acción de sus actores. El papel de las universidades. En C. Puig. (Coord.), Economía Social y Solidaria: conceptos, prácticas y políticas públicas (pp. 15-39). Vitoria: Universidad del País Vasco.

Consejo Nacional de Política Económica y Social-Conpes 3931. (2018). Política Nacional para la Reincorporación Social y Económica de exintegrantes de las (FARC-EP). Recuperado de: https://www.reincorporacion.gov.co/es/Documents/conpes_finlal_web.pdf

Escobar, A. (2013). En el trasfondo de nuestra cultura: la tradición racionalista y el problema del dualismo ontológico. Tabula Rasa, (18), 15.42.

Fomentamos. (2019). Círculos Solidarios. Recuperado de http://www. fomentamos.com.co

Freire, P. (1997). Pedagogía de la autonomía. México: Siglo XXI Editores.

Freire, P. (2005). Pedagogía del oprimido. México: Siglo XXI Editores.

Freire, P. (2011). La educación como práctica de la libertad. México: Siglo XXI Editores. 
Freire, P. (2012). Pedagogía de la indignación. Cartas pedagógicas en un mundo revuelto. Buenos Aires: Siglo XXI Editores.

Gaiger, L. (2007). La economía solidaria y el capitalismo en la perspectiva de las transformaciones históricas. En J. Coraggio, Economía social desde la periferia. Contribuciones latinoamericanas (pp. 70-109). Buenos Aires: Editorial Altamira.

Gaiger, L. (2012). Por um Olhar Inverso: prismas e questões de pesquisa sobre a Economia Solidária. Revista Sociedade e Estado, 27(2). 313-335. Recuperado de: https://periodicos. unb.br/index.php/sociedade/article/view/5655/5148

Gaiger, L. (2015). A economia solidária na contramarchada pobreza. Sociologia, Problemas e Práticas, 79, 43-63. doi: 10.7458/SPP2015793556

Ghiso, A. (2001). Potenciando la diversidad. (Diálogo de saberes, una práctica hermenéutica colectiva). Boletín Electrónico Surá, 54, 1-14. Recuperado de: http:/www.ts.ucr.ac.cr/ binarios/sura/sura-0054.pdf

Ghiso, A. 2009. Pedagogía Social en América Latina: Legados de Paulo Freire. Relaciones, Serie: R-Educación, XXIV, 1-11. Recuperado de: http://www.ecominga.uqam.ca/PDF/ lectura/Alfredo_Gisho.pdf

Ghiso, A. y Tabares-O-Ochoa, C. M. (2011). Reflexividad dialógica en el estudio de jóvenes y prácticas políticas. Revista Latinoamericana de Ciencias Sociales, Niñez y Juventud, 1(9), 129-140

Ghiso, A. (2017). Reflexividad dialógica, como experiencia de epistemes sentipensantes y solidarias. Ágora USB, 17(1), 255-264.

Ghiso, A. (2018). Conversaciones. Entre el legado de los que me preceden y mi quehacer educativo. En A. Guelman, M. Salazar y F. Cabaluz (Coord.), Educación popular y pedagogías críticas en América Latina y el Caribe: corrientes emancipatorias para la educación pública del Siglo XXI (pp. 191-220). Buenos Aires: Clacso.

Gil, J. (2018). Elogio de la contabilidad (crítica). Teuken Bidikay, 9(12), 23-54. Recuperado de: https://revistas.elpoli.edu.co/index.php/teu/article/view/1321/1068

Gómez, M. (2005). Breve introducción al estado del arte de la orientación crítica en la disciplina contable. Porik An, 10, 13-37.

Gómez, M. (2011). Pensando los fundamentos de la contabilidad como disciplina académica. Lúmina, 12, 120-150

Gómez, M. (2019). Una aproximación social, institucional y organizacional a la contabilidad. Documentos Escuela de Administración y Contaduría Pública, 35, 1-32. Recuperado de: http://www.fce.unal.edu.co/media/files/CentroEditorial/documentos/ documentosEACP/documentos-EACP-35.pdf

Gómez, M. y Ospina, C. (Ed.). (2009). Avances interdisciplinarios para una comprensión crítica de la contabilidad. Textos paradigmáticos de las corrientes heterodoxas. Medellín: Universidad Nacional de Colombia - Universidad de Antioquia.

Gómez, Y., Palacios, J. y Restrepo, J. (2015). Círculos Solidarios: Experiencias de economía alternativa para combatir la pobreza. Asia Pacífico: Principal Foco de Negocios del siglo XXI, Una Mirada para la Educación de la Economía Global. Asamblea anual del Consejo Latinoamericano de Escuelas de Administración - CLADEA, Viña del Mar, Chile. 
Gallón, N., Gómez, Y. y Rodríguez, M. Contabilidad popular. Una alternativa socio-práxica...

Guerra, P. (2010). La economía solidaria en Latinoamérica. Papeles de relaciones ecosociales y cambio global, (110), 67-76. Recuperado de: http://base.socioeco.org/docs/la_ economia_solidaria_en_latinoamerica_p_guerra.pdf

Guerra, P. (2013). Un acercamiento teórico a la autogestión para comprender las prácticas de economía solidaria en América Latina, Revista Latinoamericana de Autogestión y Acción Comunal, 61-62-63, 97-124. Recuperado de: http://www.ridaa.es/ridaa/index. php/ridaa/article/viewFile/93/91

Guerra, P. (2014). La construcción de una socioeconomía solidaria como fenómeno comunitarista: el caso latinoamericano. En J. Ramón. (Comp.), Serie de estudios sobre economía popular y solidaria. Contextos de la "Otra economía" (pp. 11-24). Quito: Superintendencia de Economía Popular y Solidaria.

Jara, O. (2018). Aportes de los procesos de educación popular a los procesos de cambio social. En A. Guelman, M. Salazar y F. Cabaluz (Coord.), Educación popular y pedagogías críticas en América Latina y el Caribe: corrientes emancipatorias para la educación pública del Siglo XXI (pp. 221-255). Buenos Aires: Clacso.

Jiménez, R. y Mora, C. (2012). Representación en los estándares internacionales de información financiera. Lúmina, 13, 128-151. Recuperado de: http://revistasum. umanizales.edu.co/ojs/index.php/Lumina/article/view/686/806

Llorente, M. y Méndez, M. (2019). La reincorporación de las FARC tres años después. Desafíos y propuestas. Bogotá: Fundación Ideas para la Paz. Recuperado de: http://ideaspaz.org/ media/website/FIP_ReincorporacionFARC_web_FINAL.pdf

Martínez, H. y Lefebvre, L. (2019). La reincorporación económica de los excombatientes de las FARC. Retos y riesgos a futuro. Bogotá: Fundación Ideas para la Paz. Recuperado de: http://ideaspaz.org/media/website/FIP_NE_Reincorporacion.pdf

Martínez, G. (2014). La contabilidad frente a la hegemonía de racionalidad calculante. Lúmina, 15, 72-105. Recuperado de: http://revistasum.umanizales.edu.co/ojs/index. php/Lumina/article/view/1072/1177

Miller, P. y O leary, T. (1987). Accounting and the construction of the governable person. Accounting, Organizations and Society, 12(3), 235-265.

Miller, P. (1994). Accounting as Social and Institutional Practice: an introduction. In Accounting as Social and Institutional Practice. Cambridge University.

Miller, P. y Power, M. (2013). Accounting, Organizing, and Economizing: Connecting Accounting Research and Organization Theory. The Academy of Management Annals, 7(1), 555-603. doi: http://dx.doi.org/10.1080/19416520.2013.783668

Potter, B. (2005). Accounting as a social and institutional practice: perspectives to enrich our understanding of accounting change. Abacus, 41(3), 265-289.

Quijano, O. (2016). La conversación o el 'interaccionismo conversacional'. Pistas para comprender el lado oprimido del(os) mundo(s). Calle 14. Revista de investigación en el campo del arte, 11(20), 34-53. doi: https://doi.org/10.14483/udistrital.jour. c14.2016.3.a03

Razeto, L. (1994). Fundamentos de una Teoría Económica Comprensiva. Santiago de Chile: Ediciones PET.

Razeto, L. (1997). Los caminos de la economía solidaria. Buenos Aires: Grupo Editorial Lumen. 
República de Colombia. (2017). Decreto ley 899 de 2017 por el cual se establecen medidas e instrumentos para la reincorporación económica y social colectiva e individual de los integrantes de las FARC-EP conforme al Acuerdo Final, suscrito entre el Gobierno Nacional y las FARC-EP el 24 de noviembre de 2016. Bogotá: República de Colombia.

Restrepo, J, Insuasty, A. y Palacios, J. (2015). Círculos solidarios una metodología de economía alternativa en Medellín. XX Congreso Internacional de Contaduría, Administración e Informática. Ciudad de México, México.

Rodríguez, M., Gallón, N. y Gómez, Y. (2016). La contabilidad en propuestas de economía solidaria y alternativa. En-Contexto, 4(5), 185-206.

Rodríguez, M., Gallón, N. y Gómez, Y. (2018). Contabilidad Popular. Una propuesta para resignificar las prácticas contables en las organizaciones. En Y. Gómez (Ed.), Observatorio Público. Experiencias, tendencias y desafíos. Líneas de investigación para explorar los campos de las Ciencias Administrativas y de Gestión, Económicas y Contables (pp. 398-429). Medellín: Publicar-T.

Singer, P. (2007). Economía solidaria. Un modo de producción y distribución. En J. Coraggio, Economía social desde la periferia. Contribuciones latinoamericanas (pp. 59-78). Buenos Aires: Editorial Altamira.

Singer, P. (2011). La reciente resurrección de la economía solidaria en Brasil. En B. Santos. (Coord.), Producir para vivir: los caminos de la producción no capitalista (pp. 63-102). México: Fondo de Cultura Económica.

Santos, B. (2003). Crítica de la razón indolente. Contra el desperdicio de la experiencia. Bilbao: Desclée De Brouwer.

Santos, B. (2009). Una epistemología del sur. Buenos Aires: Siglo XXI Editores- Clacso.

Santos, B. (2010). Descolonizar el saber, reinventar el poder. Montevideo: Ediciones Trilce Universidad de la República.

Torres, A. (2004). La vida cotidiana de las organizaciones populares como espacio formativo. Pedagogía y Saberes, (20), 21-29.

Torres, A. (2008). Investigar en los márgenes de las ciencias sociales. Folios, (27), 51-62.

Torres, A. (2009). Investigar (desde) las fronteras: De lo popular y lo comunitario. Maguaré, (23), 207-222.

Torres, A. (2010). Educación Popular y paradigmas emancipadores. Contexto \& Educação, (83), 13-48.

Torres, A. (2014). Producción de conocimiento desde la investigación crítica. Nómadas, 40, 69-83.

Torres, A. (2018). ¿Dónde está el lado crítico de la educación popular? En A. Guelman, M. Salazar y F. Cabaluz (Coord.), Educación popular y pedagogías críticas en América Latina y el Caribe: corrientes emancipatorias para la educación pública del Siglo XXI (pp.173-189). Buenos Aires: CLACSO.

Zemelman, H. (1998). Sujeto: existencia y potencia. México: Anthropos.

Zemelman, H. (2005). Voluntad de conocer: el sujeto y su pensamiento en el paradigma crítico. Barcelona: Anthropos. 